\title{
A sea spray aerosol flux parameterization encapsulating wave state
}

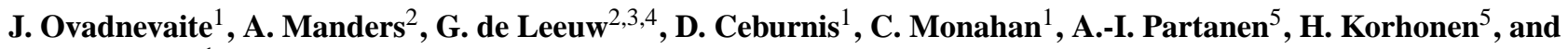 \\ C. D. O'Dowd ${ }^{1}$ \\ ${ }^{1}$ School of Physics and Centre for Climate and Air Pollution Studies, Ryan Institute, National University of Ireland Galway, \\ University Road, Galway, Ireland \\ ${ }^{2}$ TNO, Utrecht, The Netherlands \\ ${ }^{3}$ Finnish Meteorological Institute (FMI), Climate Change Unit, Helsinki, Finland \\ ${ }^{4}$ Department of Physics, University of Helsinki, Finland \\ ${ }^{5}$ Kuopio Unit, Finnish Meteorological Institute, Kuopio, Finland
}

Correspondence to: J. Ovadnevaite (jurgita.ovadnevaite@ nuigalway.ie)

Received: 11 July 2013 - Published in Atmos. Chem. Phys. Discuss.: 3 September 2013

Revised: 6 January 2014 - Accepted: 7 January 2014 - Published: 17 February 2014

\begin{abstract}
A new sea spray source function (SSSF), termed Oceanflux Sea Spray Aerosol or OSSA, was derived based on in-situ sea spray aerosol measurements along with meteorological/physical parameters. Submicron sea spray aerosol fluxes derived from particle number concentration measurements at the Mace Head coastal station, on the west coast of Ireland, were used together with open-ocean eddy correlation flux measurements from the Eastern Atlantic Sea Spray, Gas Flux, and Whitecap (SEASAW) project cruise. In the overlapping size range, the data for Mace Head and SEASAW were found to be in a good agreement, which allowed deriving the new SSSF from the combined dataset spanning the dry diameter range from $15 \mathrm{~nm}$ to $6 \mu \mathrm{m}$. The OSSA source function has been parameterized in terms of five lognormal modes and the Reynolds number instead of the more commonly used wind speed, thereby encapsulating important influences of wave height, wind history, friction velocity, and viscosity. This formulation accounts for the different flux relationships associated with rising and waning wind speeds since these are included in the Reynolds number. Furthermore, the Reynolds number incorporates the kinematic viscosity of water, thus the SSSF inherently includes dependences on sea surface temperature and salinity. The temperature dependence of the resulting SSSF is similar to that of other in-situ derived source functions and results in lower production fluxes for cold waters and enhanced fluxes from warm waters as compared with SSSF formulations that do not include temperature effects.
\end{abstract}

\section{Introduction}

Sea spray aerosol (SSA) is an important component of the aerosol population in the marine environment, and given that $70 \%$ of the Earth's surface is covered by oceans, it contributes significantly to the global aerosol budget (Vignati et al., 2010). In addition, sea spray aerosol plays an important role in climate, with both direct (Bates et al., 2006; Mulcahy et al., 2008; Vaishya et al., 2011; Rap et al., 2013) and indirect radiative effects (O'Dowd et al., 1999; Andreae and Rosenfeld, 2008). Sea spray aerosol particles are formed at the sea surface mainly through breaking waves via bubble bursting (Blanchard, 1963) and, at elevated wind speeds, by direct tearing of wave crests (Monahan et al., 1986). When a wave breaks, air is entrained into the water and dispersed into a cloud of bubbles (Thorpe, 1992), which rise to the surface and burst to produce both film and jet drops. The nearsurface wind speed, commonly measured and expressed at a reference height of $10 \mathrm{~m}, U_{10}$, is thought to be the dominant factor affecting sea spray aerosol production. However, different formulations of the size-dependent sea spray aerosol source functions (SSSF) in terms of only $U_{10}$ vary widely for the same $U_{10}$ (de Leeuw et al., 2011) and rising or waning winds produce different production fluxes (Callaghan et al., 2008; Goddijn-Murphy et al., 2011; Norris et al., 2012; Ovadnevaite et al., 2012). Considerable effort has been devoted to linking SSA production to more fundamentally relevant physical parameters, such as wind stress on the surface, or whitecap fraction, with the expectation that such 
approaches might lead to better constraining the production flux than a formulation in terms of wind speed alone. However, at a given $U_{10}$, wind stress on the surface can vary by a factor of two (Drennan et al., 2005) and whitecap fraction by a factor of 10 or more (Lewis and Schwartz, 2004; Anguelova and Webster, 2006); this variation is likely due to variability in the wave field, surface properties, and the like. Factors that are expected to affect the SSA production flux are those affecting sea state, such as fetch (the distance an air mass has travelled over the water) and atmospheric stability (often parameterized as the air-sea temperature difference), which also affects vertical transport; seawater temperature and salinity; and the presence, amount, and nature of surface-active substances. The production of sea spray aerosol was recently reviewed by de Leeuw et al. (2011) who critically examined recent laboratory and field experimental results on sea spray aerosol production, on the enrichment in organic matter, and on the measurement and parameterization of whitecap fraction, and placed it in the context of previous understanding which was comprehensively reviewed by Lewis and Schwartz (2004). The study indicated that there is still considerable uncertainty in the production of sea spray aerosol and suggested that existing submicron number flux parameterizations appear to over-predict boundary layer number concentrations compared to what is actually measured.

In this study we derive a new sea spray aerosol source function, termed Oceanflux Sea Spray Aerosol or OSSA, which covers the dry particle size range from $15 \mathrm{~nm}$ to $6 \mu \mathrm{m}$ in diameter and uses a direct fit of the size-dependent flux observations to a wave breaking parameter (Reynolds number). This approach combines the effects of wind history and wave state along with the sea surface temperature and salinity in one parameter.

\section{Approach}

\subsection{SSA flux formulation}

Sea spray aerosol generation is directly related to windinduced breaking of waves, which entrains air into the ocean surface layer. The entrained air is detrained as bubbles, which rise to the surface where they burst and produce film and jet droplets (Blanchard, 1986). The surface manifestation of a bubble plume is referred to as a whitecap and the fraction of the ocean surface covered by whitecaps, i.e. the whitecap fraction, is often used as the basis for the formulation of a sea spray aerosol source function (Lewis and Schwartz, 2004). In this so-called whitecap method, the whitecap fraction is parameterized in terms of a forcing parameter (e.g. $10 \mathrm{~m}$ wind speed or Reynolds number), and the size-dependent droplet production per unit whitecap. Hence, only the magnitude of the flux is allowed to vary with the forcing parameter (de Leeuw et al., 2011). This assumption is an oversimplifica- tion of the real environment, where the shape of the droplet size distribution could and most certainly does depend on the forcing parameter. Therefore, in this study, we incorporate the effect of the environmental forcing on both the magnitude and the shape of the SSSF. In other words, a direct relationship is assumed between the sea spray aerosol flux and the forcing parameter. Several processes would affect the bubble bursting and thus resulting aerosol or droplet size distributions; therefore, a size dependent flux parameterization is assumed to include several modes, which, at the surface, should follow a normal distribution. On the other hand, after initial formation the droplets are dispersed in the atmosphere (multiple dilutions into volume), which transforms the distribution into a lognormal distribution (Limpert et al., 2001). Since the current large-scale aerosol models cannot resolve this micro-scale aerosol dynamics, we directly assign a lognormal distribution to the source flux modes, which should thus be considered effective fluxes. Each mode is then linked to the forcing parameter, because the magnitudes of separate modes could depend on it in a different way.

\subsection{Forcing factors}

Wind waves are generated by transferring wind energy to the water surface through friction. Continuous wind stress increases the wave height until the wave breaks which in turn results in energy dissipation. Wave age and sea state will usually depend upon wind history, e.g. periods of decreasing wind speed would correspond to more developed seas with a relatively large wave age and periods of increasing wind speed should be broadly analogous to less developed seas with a relatively small wave age (Callaghan et al., 2008). Based on consideration of the energy flux from wind to waves, $\mathrm{Wu}(1979)$ proposed that wave breaking, and therefore whitecap fraction, should be proportional to $u_{*}^{3}$ or $U_{10}^{3.75}$ where $u_{*}$ is the friction velocity. At about the same time, Monahan and Muircheartaigh (1980) proposed their $U_{10}^{3.41}$ power law derived from a large amount of whitecap observation datasets. However, the wave state depends not only on the actual wind speed but also on wind history (fetch, increasing or decreasing winds), leading to developing or welldeveloped waves, with different wave steepness. Therefore, based on physical considerations of wave breaking, Zhao and Toba (2001) proposed the use of a dimensionless breaking wave parameter $\left(R_{\mathrm{b}}\right)$; however, the typical length scale to construct $R_{\mathrm{b}}$ was ambiguous and therefore was replaced by $H_{\mathrm{s}}$, which in turn led to a Reynolds number $\left(R e_{H}\right)$ expression. The latter includes the friction velocity, the height of wind waves, and the viscosity of the air. Zhao and Toba (2001) further proposed to replace the viscosity of air with the viscosity of water which is conceptually more relevant, and which was later reinforced by Woolf (2005). The resulting expression for the Reynolds number $R e_{H_{\mathrm{w}}}$ is presented below: 
$\operatorname{Re}_{H_{\mathrm{w}}}=u_{*} H_{\mathrm{s}} / \nu_{\mathrm{w}}$

Here $H_{\mathrm{s}}$ is the significant wave height and $v_{\mathrm{w}}$ is the viscosity of water. The viscosity of sea water depends on temperature and salinity (Sharqawy et al., 2010), the effects of which are thus implicitly included in a sea spray aerosol source function formulated in terms of $\operatorname{Re}_{H_{\mathrm{w}}} \cdot \operatorname{Re}_{H_{\mathrm{w}}}$ increases with increasing temperature (decreasing viscosity) and vice versa. The use of either the breaking wave parameter or the Reynolds number brings results from several laboratory experiments and in-situ observations for whitecap fraction together (Zhao and Toba, 2001), unlike the use of parameters like (non-dimensional) fetch or wave age. The good correlation between whitecap fraction and breaking wave parameter was further demonstrated by Goddijn-Murphy et al. (2011).

\subsection{SSSF expression}

Considering the reasons presented above, the OSSA SSSF is expressed as a combination of $n$ lognormally distributed modes for different droplet sizes, each of which with distinct dependency on the forcing parameter (Eq. 2). The Reynolds number was selected as the forcing parameter because of the advantages presented in Sect. 2.2.

$$
\frac{d F}{d \log D}=\sum_{i=1}^{n} \frac{F_{i}\left(R e_{H_{\mathrm{w}}}\right)}{\sqrt{2 \pi} \ln \sigma_{i}} \exp \left(-\frac{1}{2}\left(\frac{\ln \left(\frac{D}{\mathrm{CMD}_{i}}\right)}{\ln \sigma_{i}}\right)^{2}\right)
$$

Here $d F / d \log D$ is the size dependent SSA production flux, $i$ - mode number, $F_{i}\left(\operatorname{Re}_{H_{\mathrm{w}}}\right)$ - the flux for mode $i, D-$ dry particle diameter, $\sigma$-geometrical standard deviation, CMD count median diameter.

Ambient observations, described below, were used to derive the specific $F_{i}\left(R e_{H_{\mathrm{w}}}\right)$ relationships and the appropriate parameters defining the lognormal modes.

\section{Description of the data}

The source function was derived from the combination of three datasets: sub-micron particle size distributions measured at Mace Head, coarse mode SSA fluxes derived from open-ocean eddy-covariance measurements during the SEASAW cruise (Norris et al., 2012) and wave parameters obtained from the European Centre for Medium-Range Weather Forecasts (ECMWF) model. Mace Head and SEASAW data did not cover the same time and region, but both datasets are representative for the North East Atlantic during low biological productivity and cover complementary size ranges.

\subsection{Submicron particle observations}

Submicron aerosol particle size distributions were used, which were measured at the Mace Head Atmospheric Research Station in November 2010. Mace Head is located on the west coast of Ireland facing the North East Atlantic. Station details are described in O'Connor et al. (2008). All aerosol instruments are located in the shore laboratory at about $100 \mathrm{~m}$ from the coastline. They are connected to the laminar flow community air sampling system, which is constructed from a $100 \mathrm{~mm}$ diameter stainless-steel pipe with the main inlet at $10 \mathrm{~m}$ above ground level. The performance of this inlet is described in Kleefeld et al. (2002). Details on the representativeness of marine aerosol measured at Mace Head for open-ocean conditions can be found in the recent study by O’Dowd et al. (2013).

Aerosol size distributions and number concentrations were measured using a scanning mobility particle sizer (SMPS) system. The system comprised of a differential mobility analyser (DMA, TSI model 3071), a condensation particle counter (TSI model 3010), and an aerosol neutralizer (TSI 3077). Before their sizes were measured, the particles were dried to a relative humidity below $40 \%$.

The wind speed and direction were measured on the $10 \mathrm{~m}$ tower by a Vector Instruments wind monitor (model W200P/ A100L).

Aerosol chemical composition was measured using a High Resolution Time of Flight Aerosol Mass Spectrometer (HRToF-AMS or AMS) (DeCarlo et al., 2006) which was routinely calibrated following the methods described by Jimenez et al. (2003) and Allan et al. (2003). The HR-ToF-AMS measurements were performed with a time resolution of $5 \mathrm{~min}$ and a vaporizer temperature of $\sim 650{ }^{\circ} \mathrm{C}$. The composition dependent collection efficiency (CE) (Middlebrook et al., 2012) was applied for the measurement periods discussed in this study. Sea salt concentrations were measured following the method described in Ovadnevaite et al. (2012).

Data obtained during the occurrence of a plume with elevated sea salt concentrations over the North East Atlantic, see Ovadnevaite et al. (2012) for details, were used to derive the submicron SSSF. The plume was detected as the wind direction backed northerly into the clean sector at Mace Head (between $190^{\circ}-300^{\circ}$ ) and the wind speed increased to a peak value of $26 \mathrm{~m} \mathrm{~s}^{-1}$. Sea salt plumes measured by the HR-ToFAMS coincided with an increase in aerosol hygroscopicity from a typical sulphate hygroscopic growth factor (GF) of 1.6 to a GF of 2.2, which is characteristic of pure sea salt particles. As the measurements were undertaken during the winter when biological activity was low, all other chemical compounds approached very low background "winter" concentrations (e.g. non-sea salt sulphate mass $<10 \mathrm{ng} \mathrm{m}^{-3}$; organic mass $<60 \mathrm{ng} \mathrm{m}^{-3}$; black carbon mass $<10 \mathrm{ng} \mathrm{m}^{-3}$; nitrate mass $<17 \mathrm{ng} \mathrm{m}^{-3}$ and ammonium mass below the detection limit of $38 \mathrm{ng} \mathrm{m}^{-3}$ ).

\subsection{Super-micron particle observations}

Since Mace Head data covers only the submicron part of the SSSF, fluxes of larger sea spray aerosol particles measured during the SEASAW campaign (described and analysed in 
detail in Norris et al., 2012) were used to complement the Mace Head derived SSSF. The SEASAW open-ocean flux dataset consists of 111 valid measurements obtained during a cruise in the Eastern North Atlantic Ocean, 21 March12 April 2007. Wind speed conditions ranged from 3 to $18 \mathrm{~m} \mathrm{~s}^{-1}$, and the ship was actively relocated to areas with high wind speed conditions. The biological activity, estimated from satellite data and aerosol volatility measurements, was low. Data were obtained with the Compact Lightweight Aerosol Spectrometer Probe (CLASP) (Hill et al., 2008), measuring aerosol particle concentrations in 16 size channels covering a range of $0.17-9.5 \mu \mathrm{m}$ radius at ambient relative humidity. Sea spray aerosol fluxes were measured using the eddy covariance technique, with sampling records of $28 \mathrm{~min}$.

Flux estimates were corrected for the relative humidity flux, and results were harmonized to represent fluxes for particle radii at $80 \%$ relative humidity. In the literature, it is common to use either the dry particle diameter $\left(D_{\text {dry }}\right)$ or the radius at $80 \% \mathrm{RH}\left(R_{80}\right)$; in fact these two conventions come down to the same numerical value as for sea salt particles a wet radius at $80 \% \mathrm{RH}$ equals the dry diameter. When using these data to derive an SSSF, there are some limitations which should be mentioned. Firstly, the scatter in the data was considerable (order of magnitude), which is inherent to the measurement technique. Secondly, a net flux was measured, which includes both the production flux and the deposition. Norris et al. (2012) indicate that the difference between the production flux and the net flux is important for super-micron particles larger than about $R_{80}=5 \mu \mathrm{m}$, however, this difference becomes insignificant for particles smaller than $1 \mu \mathrm{m}$.

\subsection{Wave data}

Wave data from the ECMWF wave model (WAM) were used in this study to derive the Reynolds number from wave characteristics. Data were globally available on $6 \mathrm{~h}$ basis at a $0.5 \times 0.5^{\circ}$ longitude-latitude resolution. The ECMWF ReAnalysis (ERA-interim) product was used to get a consistent dataset over several years. We have used the wind velocity, mean drag coefficient, and significant height of wind waves. WAM assimilates wave height data derived from satellite altimetry data (Abdalla et al., 2010).

\section{Derivation}

\subsection{The expression of the Reynolds number}

The $R e_{H_{\mathrm{w}}}$ expression used in this paper (Eq. 3) is obtained by replacing $u_{*}$ in Eq. (1) with $u_{*}=C_{d}^{1 / 2} U_{10}$. To avoid an influence from a swell component, only the wind wave part of the wave height, as provided by ECMWF, was used in the
SSSF derivation.

$R e_{H_{\mathrm{w}}}=C_{\mathrm{d}}^{1 / 2} U_{10} H_{\mathrm{s}} / v_{\mathrm{w}}$

This replacement of $u_{*}$ only holds for neutral conditions. However, this approach is deployed in WAM, which output $\left(H_{\mathrm{s}}, C_{\mathrm{d}}\right.$ and $\left.U_{10}\right)$ is used in this study. In addition, it takes into account the calculated wave state: the WAM model is coupled to the ECMWF atmosphere model with a correction for the Charnock parameter based on the wave stress in the feedback of the wave model to the atmosphere model (IFS, 2011). Foreman and Emeis (2010) proposed a new relationship between $u^{*}$ and $U_{10}$, based on a fit to wind and wave observations, later modified by Andreas et al. (2012), which could be an alternative to the formulation that we have used, but then the coupling to wave state and the internal consistency in our dataset would be lost. More importantly, their average relationships cannot resolve the subtleties of the effect of rising or waning winds or fetch on wave state, which is included in WAM. It is interesting to note that in the parameterizations of Foreman and Emeis (2010) and Andreas et al. (2012), a distinction is made in fit parameters between wind speeds smaller than or larger than $8-9 \mathrm{~m} \mathrm{~s}^{-1}$, related to the transition to rough flow, with impact on the drag. Such distinction between different wind speed regimes has also been made in studies on whitecap parameterization (Callaghan et al., 2008; Goddijn-Murphy et al., 2011); however without reference to this transition to rough flow. The direct use of $u_{*}$ in the parameterization has the advantage that the need to separate into different wind speed regimes disappears, provided that the relationship between $u_{*}$, wind speed and drag is realistic. The fact that we did not see any transition in our source function for different wind speed regimes, as opposed to what is usually seen in wind speed-only source functions, supports the idea that our approach captures the main features.

Moreover, using the SSSF based on wind speed only, the mass flux for waning winds significantly exceeds the flux for rising winds (Ovadnevaite et al., 2012) and the flux-wind speed dependencies for these two different wind conditions is clearly separated (Fig. 1, right panel, and Ovadnevaite et al., 2012). For the new SSSF, parameterized in terms of $R e_{H_{\mathrm{w}}}$, the difference between rising and waning winds disappeared. This not only reduced the scatter $\left(R^{2}\right.$ improved from 0.95 to 0.98 and chi square reduced from 16.4 to 5.8 ) but the relationships for rising or waning winds started to inter-cross (Fig. 1, left panel), which also indicated that remaining data point scatter was due to a data measurement or derivation uncertainty rather than a real physical effect coming from the wave state.

\subsection{Submicron SSA flux calculations}

Submicron SSA fluxes were derived from the particle number concentration measurements using the following assumptions. Submicron aerosol particles were expected to 

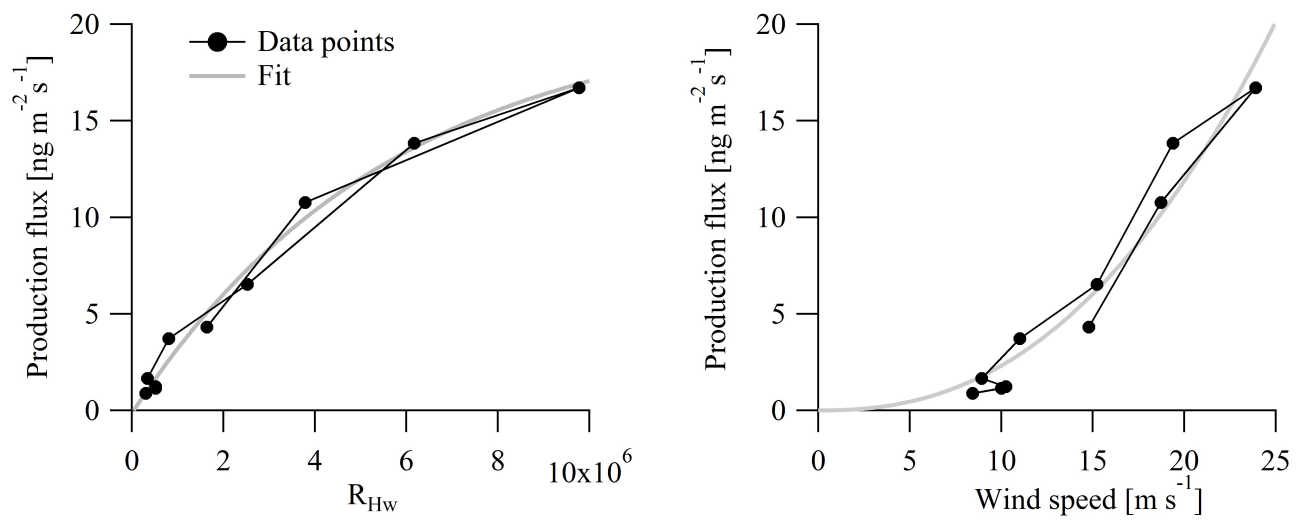

Fig. 1. Production Flux dependence on the Reynolds number, $R_{H_{\mathrm{w}}}$, (left panel) and wind speed (right panel). For the data points presented here, the wind speed was initially increasing then levelling off and eventually decreasing, therefore, intercrossing lines for the relationship on the left panel - Flux vs. Reynolds number - indicate that there is no separation between the two regimes (increasing and decreasing wind speed), however, Flux vs. Wind speed (right panel) indicates distinctly different relationships for the different regimes, especially at higher winds.

be uniformly mixed in the marine boundary layer (Lewis and Schwartz, 2004), thus an effective SSA production flux, $F_{\text {eff }}$, was estimated from the SSA number concentration $(N)$ divided by a filling time $(\tau)$ and multiplied by the marine boundary layer height $\left(H_{\mathrm{MBL}}\right)$ :

$F_{\text {eff }}=\frac{N \times H_{\mathrm{MBL}}}{\tau}$

The atmospheric boundary layer height was derived from ground-based LIDAR measurements using the Temporal Height Tracking (THT) algorithm (Haeffelin et al., 2012; Milroy et al., 2012). The marine boundary layer typically consists of two layers, with a surface mixed layer (SML) and a decoupled residual or convective layer (DRCL) above which is the free troposphere (Milroy et al., 2012). SML values were used in the flux calculations and were observed to vary between 720 and $1290 \mathrm{~m}$ above ground level over the plume duration period. SML height derived over Mace Head was comparable to the relatively steady mixing layer depth over the ocean observed along the air mass back trajectories. Nonetheless, remaining differences between the SML and the marine boundary layer height contributed to the SSSF uncertainties.

The filling time $\tau$ was assumed to be approximately 1.52 days, as discussed in Ovadnevaite et al. (2012) who used a similar method to derive the submicron sea spray aerosol mass flux.

The local wind speed at Mace Head was representative of open ocean conditions further upwind, obtained from the National Oceanic and Atmospheric Administration (NOAA) Air Resources Laboratory, as illustrated in Fig. 2a. Moreover, Fig. $2 \mathrm{c}-\mathrm{d}$ indicate the good agreement between wind speeds measured at Mace Head and the wind speeds modelled by ECMWF for the area upwind to Mace Head (Fig. 2b) which, together with ECMWF model data for significant wave heights and drag coefficients, was used to calculate $R e_{H_{\mathrm{w}}}$. Since ECMWF data were provided with a resolution of only 6 hours, too coarse for application to the relatively short event studied here, they were interpolated to a resolution of $10 \mathrm{~min}$. Modelled, interpolated and measured data are presented in Fig. 2c, d.

Although the background mass concentration (as measured at $\sim 4 \mathrm{~m} \mathrm{~s}^{-1}$ wind speed) was insignificant (Ovadnevaite et al., 2012), the background number size distribution was subtracted from the number distributions measured at higher wind speeds.

Using deposition velocities provided in (Hoppel et al., 2002), the dry deposition was found to be negligible for the submicron particles, except for the very small nano-metric size particles or for the super-micron ones; however, the error introduced due to deposition at these sizes would still be within the uncertainties provided for the OSSA source function. During the period of Mace Head observations used here, there were practically no clouds or precipitation and therefore the contribution of wet-deposition and coalescence removal processes to the total flux were negligible.

\subsection{OSSA-SSSF}

The size dependent SSA production flux $(d \mathrm{~F} / d \log D)$ was obtained by combining a submicron aerosol flux, derived from $\mathrm{d} N / \mathrm{d} \log D$ data (measured by SMPS) and calculating $F$ from $N$ using Eq. (3), with the measured super-micron $d F / d \log D$ data and averaged over $1 \mathrm{~m} \mathrm{~s}^{-1}$ wind speed bins. An average Reynolds number was also calculated for each of these bins. Combined $d F / d \log D$ data points are presented in Fig. 3 for different wind speeds. In the overlapping size range (at $\sim 300 \mathrm{~nm}$ ) the two datasets show very good agreement, except for the measurements at the lowest and the highest wind speeds, although these were still within 
a)

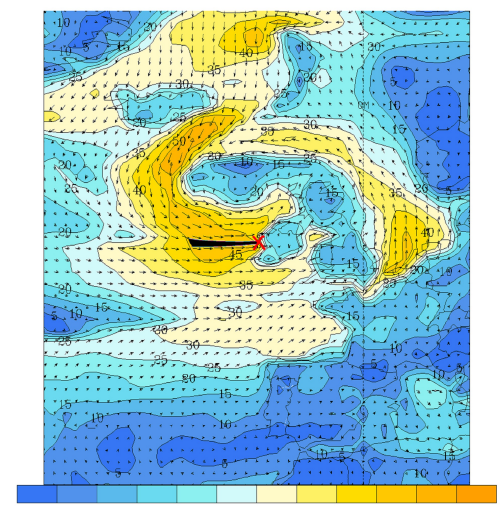

$0 \quad 5 \quad 1015202530354045505560$ Wind speed [knts]

c)

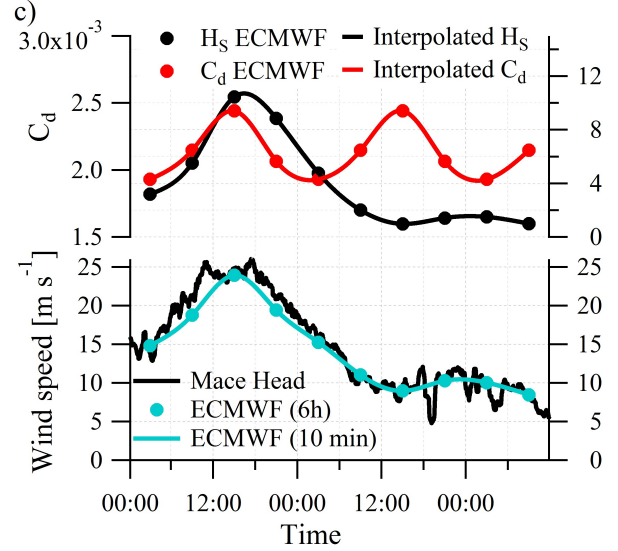

b)

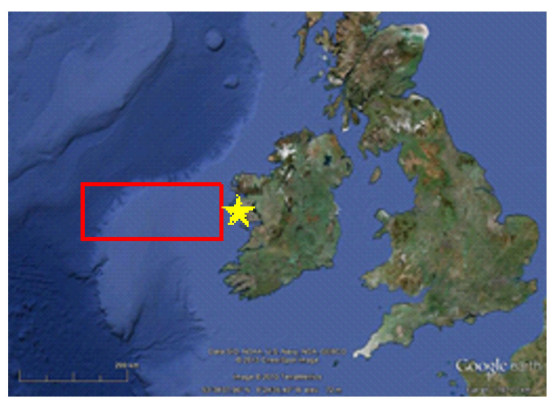

d)

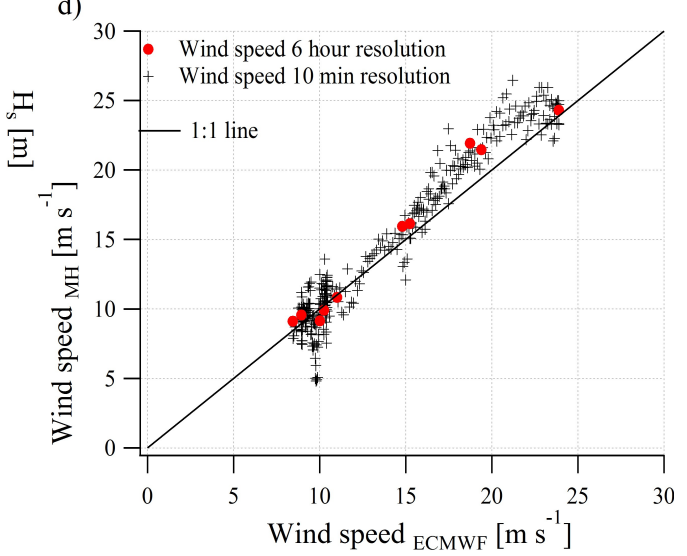

Fig. 2. (a) Wind speed field (in knots) for 12:00 UTC 11 November 2010 obtained from the NOAA Air Resources Laboratory. The local wind speed of $24.1 \mathrm{~m} \mathrm{~s}^{-1}$ (46.8 knots) measured at Mace Head (red cross) was in the range of upwind wind speed presented by NOAA (45-50 knots), the black line represents the $3 \mathrm{~h}$ air mass back trajectories with the end time of 12:00 UTC 11 November 2010 and at three heights: 100, 500, $1000 \mathrm{~m}$ above the ground level; (b) map of Mace Head location (a yellow star); the red rectangle indicates the area over which the ECMWF parameters were averaged; (c) Time series of wind speed measured at Mace Head (MH) and wind speed and wave parameters modelled by ECMWF: $H_{\mathrm{S}}$ - significant height of wind waves, $C_{\mathrm{d}}-$ drag coefficient due to wind waves used for $R e_{H_{\mathrm{w}}}$ calculations; markers represent original $6 \mathrm{~h}$ ECMWF resolution, lines represent the interpolated data to obtain the higher time resolution used for the parameterization. (d) Wind speed measured at Mace Head vs. ECMWF modelled wind speed over the area upwind to Mace Head (red area in (b)). Red circles represent the original ECMWF resolution and averaged Mace Head measurement, black crosses - 10 min measurement averages vs. interpolated ECMWF data.

the uncertainty limits described above. For every wind speed bin, five lognormal size distributions were fitted to the resulting $d F / d \log D$ distribution (Fig. 4). This resulted in a five-modal SSA flux formulation in terms of the Reynolds number $\operatorname{Re}_{H_{\mathrm{w}}}$ with different coefficients for each mode (Eq. 2 with $n=5$ ).

All parameters used in Eq. (2) are listed in Table 1, including the SSA production flux relationship with $\operatorname{Re}_{H_{\mathrm{w}}}$ through the $F_{i}\left(R e_{H_{\mathrm{w}}}\right)$.

The dependence of $F_{i}$ on $\operatorname{Re}_{H_{\mathrm{w}}}$ is shown in Fig. 4b together with the measurement data. The $R e_{H_{\mathrm{w}}}$ dependence is distinctly different for each mode, which confirmed the assumption, raised in the "Approach" section, that the forcing parameter affects the production of particles of different
Table 1. Lognormal parameters for the SSSF parameterization. For each mode, a geometric standard deviation $\left(\sigma_{i}\right)$, count-median diameter $\left(\mathrm{CMD}_{i}\right)$, and the total number flux $\left(F_{i}\right)$ as a function of Reynolds number $\left(R e_{H_{\mathrm{w}}}\right)$ are given.

\begin{tabular}{llll}
\hline$i$ & $\sigma_{i}$ & $\mathrm{CMD}_{i}$ & $\mathrm{~F}_{i}\left(\operatorname{Re}_{H_{\mathrm{w}}}\right)$ \\
\hline 1 & 1.37 & 0.018 & $104.5\left(\operatorname{Re}_{H_{\mathrm{w}}}-1 \times 10^{5}\right)^{0.556}$ \\
2 & 1.5 & 0.041 & $0.0442\left(\operatorname{Re}_{H_{\mathrm{w}}}-1 \times 10^{5}\right)^{1.08}$ \\
3 & 1.42 & 0.09 & $149.6\left(\operatorname{Re}_{H_{\mathrm{w}}}-1 \times 10^{5}\right)^{0.545}$ \\
4 & 1.53 & 0.23 & $2.96\left(\operatorname{Re}_{H_{\mathrm{w}}}-1 \times 10^{5}\right)^{0.79}$ \\
5 & 1.85 & 0.83 & $0.51\left(\operatorname{Re}_{H_{\mathrm{w}}}-2 \times 10^{5}\right)^{0.87}$ \\
\hline
\end{tabular}




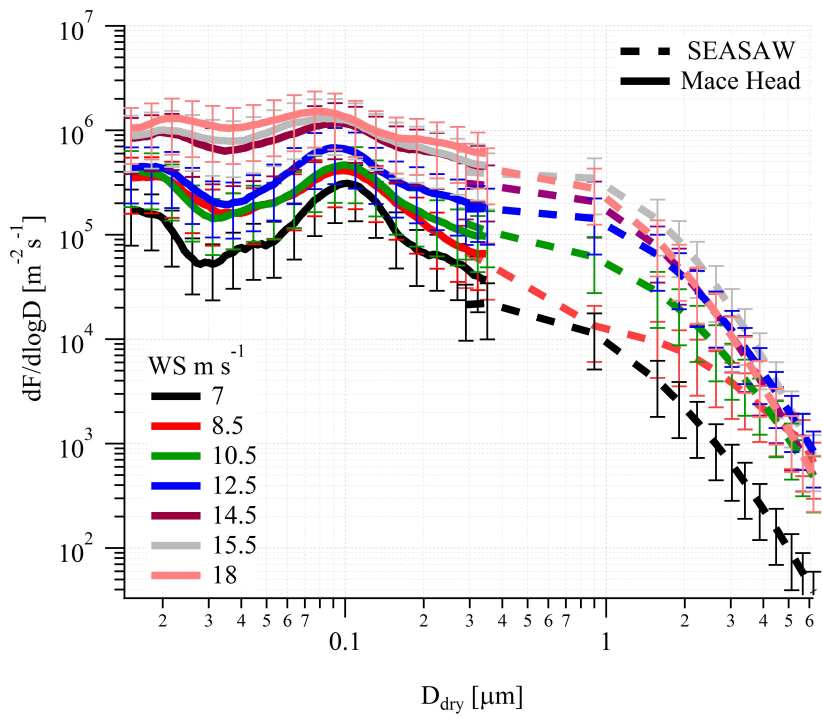

Fig. 3. $d F / d \log D$ at different wind speeds: solid lines represent Mace Head data and dashed lines represent SEASAW measurements, error bars represent measurement and method uncertainties described in the Sect. 3.3.

sizes differently. The study by Monahan et al. (1986) indicated various wind speeds for the onset of the production by different mechanisms. Therefore, separate intercepts for submicron and super-micron aerosol particles $\left(R e_{H_{\mathrm{w}}}\right.$ at $1 \times 10^{5}$ and $2 \times 10^{5}$ respectively in Table 1$)$ were anticipated. The $R e_{H_{\mathrm{W}}}$ threshold for submicron particles is consistent with results from the study by Callaghan et al. (2008), which suggested a wind speed threshold for the onset of wave breaking at $\sim 3.7 \mathrm{~m} \mathrm{~s}^{-1}$, corresponding to $R e_{H_{\mathrm{w}}} \sim 1 \times 10^{5}$ at given wave height and sea surface temperature (SST) conditions $\left(H_{\mathrm{S}}=1.23, \mathrm{SST}=9^{\circ} \mathrm{C}\right)$.

\subsection{Error propagation}

The SSSF uncertainty was evaluated by applying error propagation rules (Taylor, 1997). The submicron aerosol flux was calculated from the number concentration $(N)$, the boundary layer height $\left(H_{\mathrm{MBL}}\right)$ and the filling time $(\tau)$ (see Eq. 3), therefore, the resulting uncertainty was equal to $\sqrt{\Delta N^{2}+\Delta H_{\mathrm{MBL}}^{2}+\Delta \tau^{2}}$. The SMPS measurement uncertainty $\Delta N \sim 10-20 \%, \Delta D \sim 5 \%$ (Wiedensohler et al., 2012), $\Delta H_{\mathrm{MBL}} \sim 15-20 \%$ (Milroy et al., 2012) and $\Delta \tau \sim 50 \%$ (Ovadnevaite et al., 2012), therefore, the resulting submicron SSSF uncertainty is in the range of 55-60\%.

Since the derived Reynolds number was used instead of direct $U_{10}$ measurements, the uncertainty due to $R e_{H_{\mathrm{w}}}$ calculations (see Eq. 2) was evaluated accordingly: $\sqrt{\Delta C_{d}^{2}+\Delta U_{10}^{2}+\Delta H_{\mathrm{s}}^{2}}$; the uncertainty in $\Delta H_{\mathrm{s}}$ is $\sim 2-$ $5 \%, \Delta U_{10} \sim 10 \%, \Delta C_{d} \sim 15 \%$ (Janssen et al., 2007; Abdalla et al., 2011), which resulted in an overall $R e_{H_{\mathrm{w}}}$ uncertainty of $\sim 20 \%$.
Super-micron aerosol measurement and eddy covariance method uncertainties were presented in the study by Norris et al. (2012), Sects.2.2 and 2.3.

\section{Results}

Measured and parameterized fluxes for two different values of $R e_{H_{\mathrm{w}}}$ are presented in Fig. 5, which shows $d F / d \log D$ vs. $D$ together with the calculated uncertainties. Figure 5 shows that the parameterized fluxes represent the observations well within the uncertainty range, which suggests that the main driving processes were captured correctly.

\subsection{SSSF intercomparison}

The OSSA-SSSF has been evaluated by comparing the resulting sea spray aerosol mass with independent HR-ToFAMS measurements at Mace Head, which were not used in the derivation of the OSSA-SSSF. However, the data can only be used to validate the submicron part of the spectrum. In order to achieve this, the OSSA number flux was simulated for a particle size range directly comparable to the HRToF-AMS measurement size range $\left(D_{\text {dry }}=0.03-0.58 \mu \mathrm{m}\right.$ or vacuum aerodynamic diameter, as measured in the HR-ToFAMS, $\left.D_{\text {va }}=0.05-1 \mu \mathrm{m}\right)$, converted to a corresponding mass flux and integrated over the size range. This was done for a range of wind speeds and the results are shown in Fig. 6, together with HR-ToF-AMS derived mass fluxes (Ovadnevaite et al., 2012) and the respective uncertainties. The production flux derived using the OSSA-SSSF is within the uncertainty ranges of the HR-ToF-AMS mass fluxes although it overestimates the mass concentration from $0 \%$ (at $5 \mathrm{~m} \mathrm{~s}^{-1}$ wind speed) to $80 \%$ (at $20 \mathrm{~m} \mathrm{~s}^{-1}$ wind speed). However, the agreement between the OSSA-SSSF and the HR-ToF-AMS derived SSA mass fluxes is significantly better than that between HR-ToF-AMS and other SSSFs presented in Ovadnevaite et al. (2012). The largest discrepancy between the SSA mass fluxes obtained with the OSSA-SSSF and measured with the HR-ToF-AMS is due to the large uncertainty in super-micron aerosol distributions (see SEASAW description in Sect. 2) since SSA particles in this size range have the highest contribution to the SSA mass. As shown in Fig. 4, particles in mode 5 contribute significantly to the submicron aerosol number concentration (see $F_{5}$ in Fig. 4a) and therefore also to the resulting mass flux together with the inherent uncertainties.

In addition, the variation in the HR-ToF-AMS aerodynamic lens cut-off could have had an effect on the mass concentrations measured by the HR-ToF-AMS. The typical HR-ToF-AMS aerodynamic lens cut-off of $1 \mu \mathrm{m}$ (50\% transmission efficiency for the $D_{\mathrm{va}}$ of $1 \mu \mathrm{m}$ or mobility diameter, $D_{\mathrm{m}}$, of $0.58 \mu \mathrm{m}$ ) was applied to the number flux derived from this study in order to compare different methods. However, the best agreement between the masses derived from 

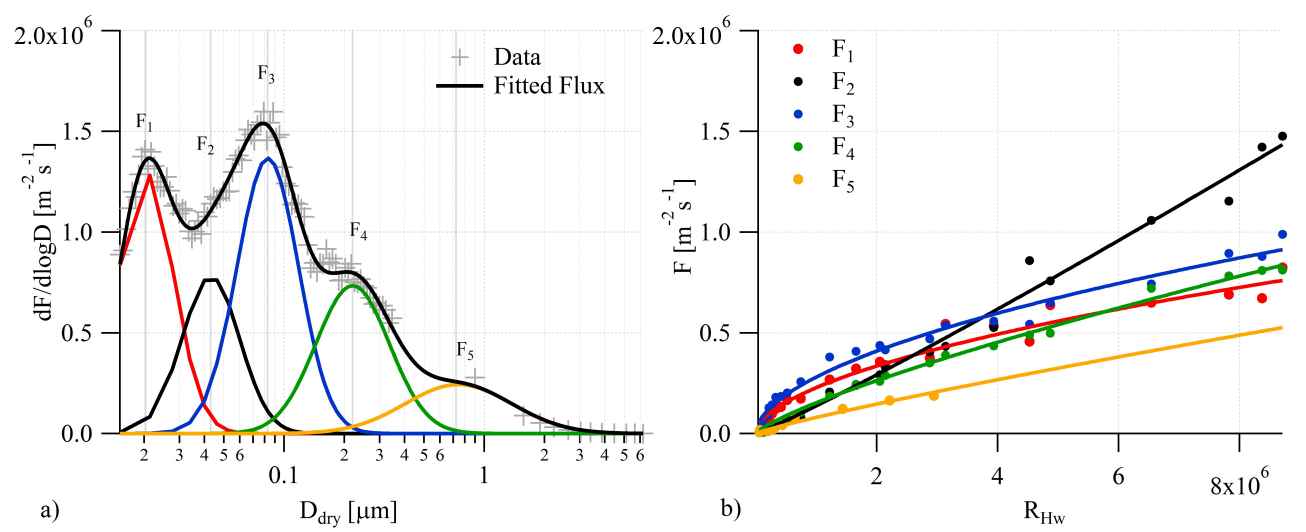

Fig. 4. (a) Parameterization of the size-dependent sea spray aerosol flux at $\operatorname{Re}_{H_{\mathrm{w}}}=3.1 \times 10^{6}\left(U_{10} \sim 18 \mathrm{~m} \mathrm{~s}^{-1}\right)$ : markers represent the measured data points, the solid black line represents the parameterization and thin lines represent individual lognormal modes; (b) SSA flux versus $\operatorname{Re}_{H_{\mathrm{w}}}$ for the different size modes. Markers represent the measured data points, lines are the fitted power laws used in the parameterization (mode amplitudes $F_{i}$, Table 1).

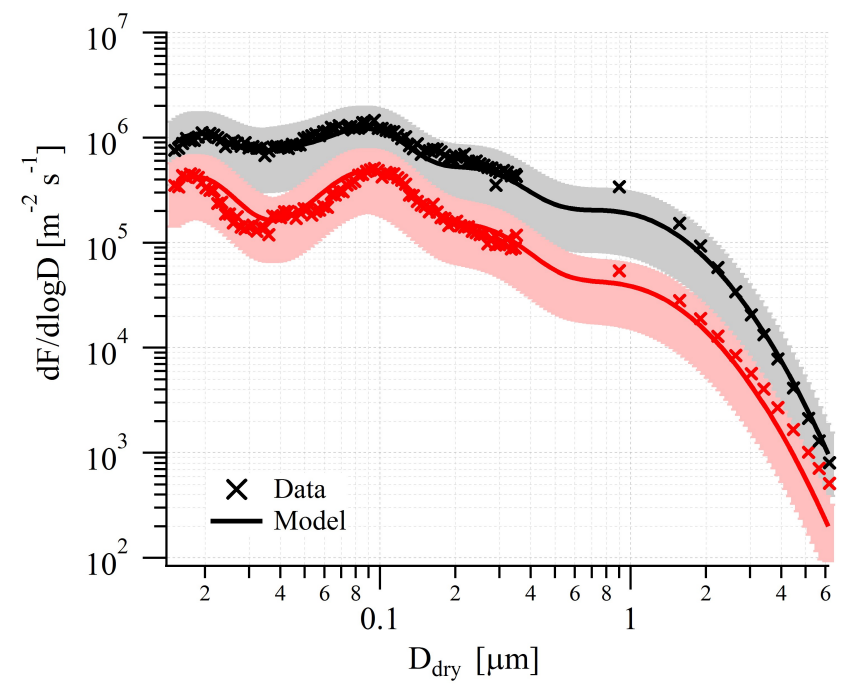

Fig. 5. Size dependent SSSF at two different $R e_{H_{\mathrm{w}}}$, red at $5.2 \times 10^{5}$ $\left(\sim 10 \mathrm{~m} \mathrm{~s}^{-1}\right)$ and black at $2.2 \times 10^{6}\left(\sim 15 \mathrm{~m} \mathrm{~s}^{-1}\right)$. Markers represent the real data measured at certain wind speed; lines represent calculations from the OSSA source function. Shaded areas represent the SSSF uncertainties.

the OSSA-SSSF and measured by the HR-ToF-AMS was achieved when an upper cut-off of $0.9 \mu \mathrm{m}$ is selected.

A comparison of the OSSA sea spray aerosol source function (OSSA-SSSF) and other commonly used or recently (last decade) developed source functions at $8 \mathrm{~m} \mathrm{~s}^{-1}$ wind speed (de Leeuw et al., 2011) is presented in Fig. 7. This wind speed was selected as the most common one in the real ambient environment (Rinaldi et al., 2013). Since the OSSA-SSSF depends on the Reynolds number instead of the wind speed directly, $R e_{H_{\mathrm{w}}}$ was calculated using Eq. (2) for a wind speed of $8 \mathrm{~m} \mathrm{~s}^{-1}$ and other parameters relevant

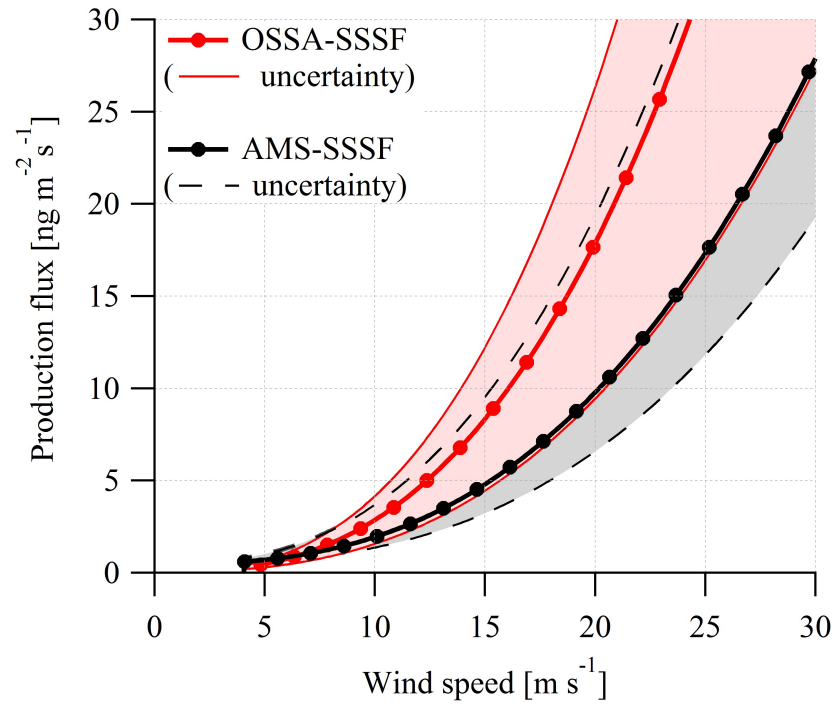

Fig. 6. Comparison between the SSA mass flux calculated using the OSSA-SSSF (see text) (Red lines) with the HR-ToF-AMS derived mass flux (Ovadnevaite et al., 2012) (Black lines) as function of wind speed. Pink and grey areas represent the associated measurement uncertainties.

to the conditions for which this source function was derived $\left(C_{\mathrm{d}}=2.15 \times 10^{-3}, H_{\mathrm{s}}=1.23, v_{\mathrm{w}}=1.34 \times 10^{-6}\right)$.

The OSSA-SSSF is on the lower side as compared to other parameterizations. As noted by de Leeuw et al. (2011) and Ovadnevaite et al. (2012), source functions based on Monahan's whitecap parameterization tend to result in higher atmospheric submicron number/mass concentrations than those typically measured. A recent European Monitoring and Evaluation Programme (EMEP) unified model intercomparison study (Tsyro et al., 2011) shows that model calculations using the Mårtensson et al. (2003) and Gong (2003) 


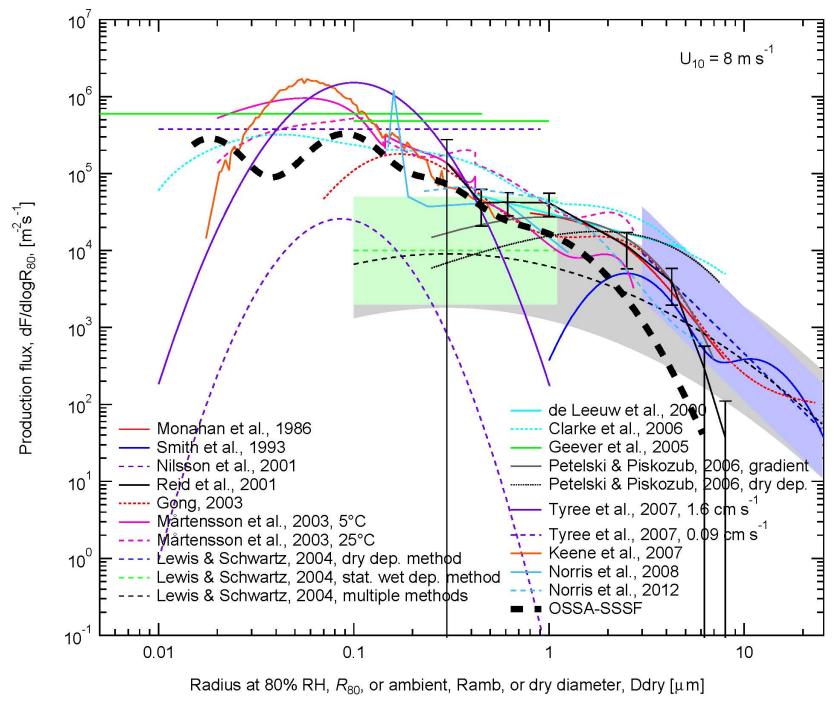

Fig. 7. Comparison of the sea spray aerosol source function derived in this study (OSSA-SSSF) with other SSSF (Monahan et al., 1986; Smith et al., 1993; de Leeuw et al., 2000; Nilsson et al., 2001; Reid et al., 2001; Gong, 2003; Mårtensson et al., 2003; Lewis and Schwartz, 2004; Geever et al., 2005; Clarke et al., 2006; Petelski and Piskozub, 2006; Keene et al., 2007; Tyree et al., 2007; Norris et al., 2008; Norris et al., 2012), evaluated for wind speed $U_{10}=8 \mathrm{~m} \mathrm{~s}^{-1}$ (or $U_{22}=8 \mathrm{~m} \mathrm{~s}^{-1}$ for Geever et al. (2005). Also shown are central values (curves) and associated uncertainty ranges (bands) from review of Lewis and Schwartz (2004), which denote subjective estimates by those investigators based on the statistical wet deposition method (green), the steady state deposition method (blue), and taking into account all available methods (gray); no estimate was provided for $R_{80}<0.1 \mu \mathrm{m}$. Lower axis denotes radius at $80 \%$ relative humidity, $R_{80}$, except for formulations of Nilsson et al. (2001), Mårtensson et al. (2003), and Clarke et al. (2006) which are in terms of dry particle diameter, $D_{\text {dry }}$, approximately equal to $R_{80}$ and those of Geever et al. (2005), Petelski and Piskozub (2006) (dry deposition method), and Norris et al. (2008), which are in terms of ambient radius, $R_{\mathrm{amb}}$. Formulations of Tyree et al. (2007) are for artificial seawater of salinity 33 at the two specified bubble volume fluxes. Formulations of Nilsson et al. (2001) and Geever et al. (2005) of particle number production flux without size resolution are plotted arbitrarily as if the flux is independent of $R_{\mathrm{amb}}$ over the size ranges indicated to yield the measured number flux as an integral over that range. (Figure and caption modified from de Leeuw et al. (2011).

SSSF overestimate atmospheric concentrations of $\mathrm{Na}$ by $8 \%$ to $46 \%$ in comparison with EMEP observations. The higher overestimation was observed for the winter season, which is consistent with the results presented in Ovadnevaite et al. (2012): the stronger flux-wind speed relationship of Mårtensson et al. (2003) or Gong (2003) would result in higher overestimation of sea salt mass concentrations during the high wind speed periods usually occurring in winter.

\subsection{An estimate of the global production flux}

Although validation of the OSSA-SSSF on a global scale was performed elsewhere (Partanen et al., 2014), it has been used for the preliminary calculation of the annual mean production flux for the year 2006. This was achieved with a simple modelling tool, developed at Netherlands Organisation for Applied Scientific Research: TNO, which calculates the fluxes based on the prescribed parameterization, and uses ECMWF meteorological and wave data as an input (Fig. 8). Mass and number fluxes were calculated for particles with dry diameters $<1 \mu \mathrm{m} .3 \mathrm{~h}$ sea surface temperature and $U_{10}$ from ECMWF Integrated Forecasting System (IFS) analysis, $6 \mathrm{~h} C_{d}$, significant height of wind waves from WAM ERAInterim and sea surface temperature (SST) dependent viscosity, assuming a constant salinity of 35\%o, were used to calculate $R e_{H_{\mathrm{w}}}$ using Eq. (2). The Reynolds number was then used in the parameterization (2) with the parameters of Table 1. It is worth noticing that appropriate salinity and thus viscosity values should be used (but not applied in this study) when the source function is applied to brackish waters such as the Baltic Sea (Mårtensson et al., 2003; Manders et al., 2010; Sofiev et al., 2011).

As expected, Fig. 9 shows higher production fluxes for the regions with stronger winds. In addition, sea surface temperature effects, incorporated in $R e_{H_{\mathrm{w}}}$ through the viscosity, enhance the production in the warm waters on both sides of the equator, and reduce it for the colder water regions with respect to an exercise in which the OSSA-SSSF was used with constant viscosity (Fig. 10).

Global instantaneous fluxes derived from the meteorological and wave data are presented in Fig. 11, which shows a comparison of these fluxes with those derived with the same modelling tool but using the Gong (2003) and Jaeglé et al. (2011) source functions. These two source functions are similar with the difference that Jaeglé et al. (2011) incorporate SST effects based on a comparison between model computations and MODIS observations of the aerosol optical depth (AOD). The comparisons were made for instantaneous global data (2 January 2006, 00:00 UTC) for number fluxes of particles with a dry diameter of $0.07<D_{\text {dry }}<0.15 \mu \mathrm{m}$ (Aitken mode) or $0.07<D_{\text {dry }}<1 \mu \mathrm{m}$ (submicron particles) and for the mass flux of particles smaller than $1 \mu \mathrm{m}$. Fluxes computed using the Gong SSSF are presented on both left and right panels in black dots, while the fluxes computed using the OSSA-SSSF are presented in coloured circles on the left panel and those using the Jaeglé SSSF in coloured circles on the right panel. The differences in the fluxes due to the SST effect, as compared to the Gong SSSF, are obvious for both the OSSA and the Jaegle et al. (2011) SSSF. Higher fluxes are produced at higher SST (red colours in the Fig. 11); while at lower temperatures (blue colours) the fluxes are lower.

In addition to the spread due to SST, the OSSA-SSSF also accounts for wave state, which reduces the effect of 

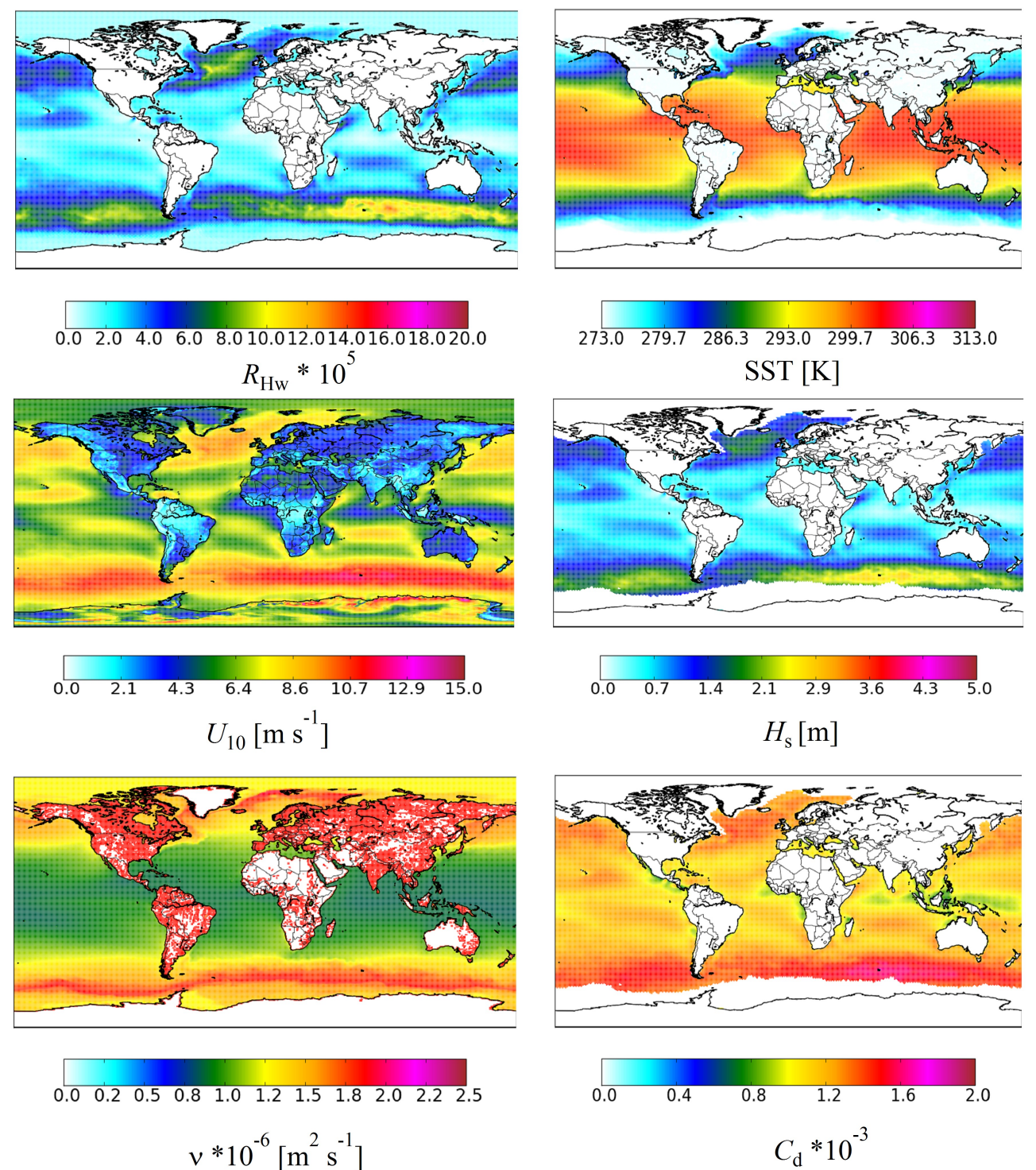

$C_{\mathrm{d}} * 10^{-3}$

Fig. 8. Annual mean values of meteorological/oceanographic fields (ECMWF) that were used for the calculation of the sea spray aerosol fluxes for 2006 .

temperature on the fluxes and brings some of the low temperature points closer to the Gong-derived fluxes. We postulate that this is due to on average larger values of the wave height and drag coefficient in the lower temperature regions (Fig. 8). As an example, the low flux values calculated using the Jaeglé SSSF at high wind speeds and at low SST (Fig. 11a, right panel) are not observed in the fluxes calculated with the OSSA-SSSF (Fig. 11a, left panel). The submicron number flux resulting from our function is quite evenly distributed around Gong's function for all wind speeds (Fig. 11a, left panel). However, the number fluxes for the Aitken mode particles, important for cloud formation, are lower than those obtained using Gong, especially at higher wind speeds (Fig. 11b, left panel). In addition, the OSSASSSF derived submicron mass fluxes are considerably lower than those derived using Gong's SSSF, at all temperatures except for the highest ones (Fig. 11c, left panel).

In order to compare the temperature dependences of the OSSA and Jaeglé et al. (2011) SSSFs and considering that the Jaeglé et al. (2011) SSSF does not have a dependency on the wind history, averaged constant values for $C_{d}$ and $H_{\mathrm{s}}$ were used in the flux calculations applied for the comparison. Although different in origin (through the viscosity in the OSSA-SSSF and through the adjustment to the in-situ measurements in the Jaegle SSSF), the variations of the SSSF with SST are similar in the sense that for both SSSFs the production increases with SST and the values for the lowest and highest temperatures are similar (Fig. 12). However, the shapes of the relationships are somewhat different. Where the OSSA-SSSF increases monotonously with SST, the Jaeglé 
a)

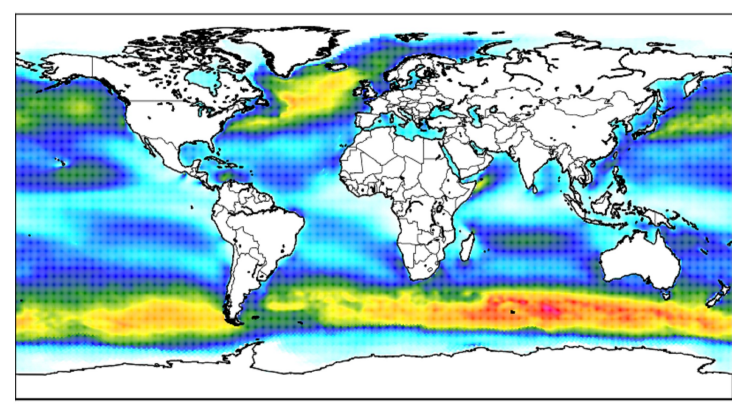

b)
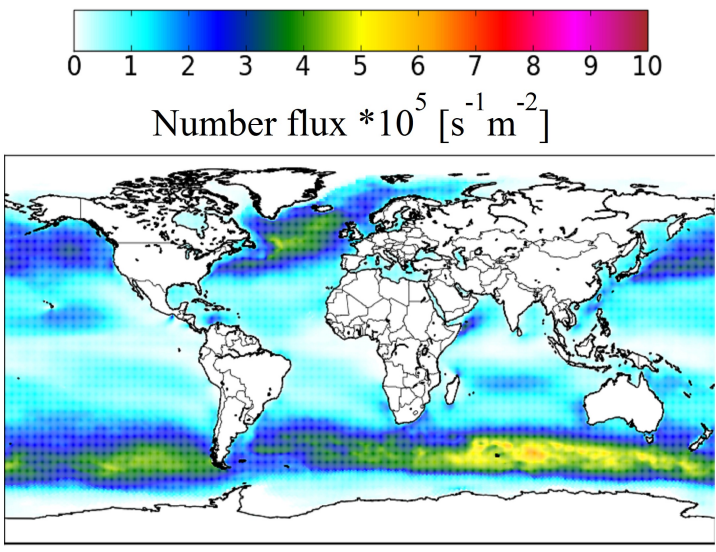

c)
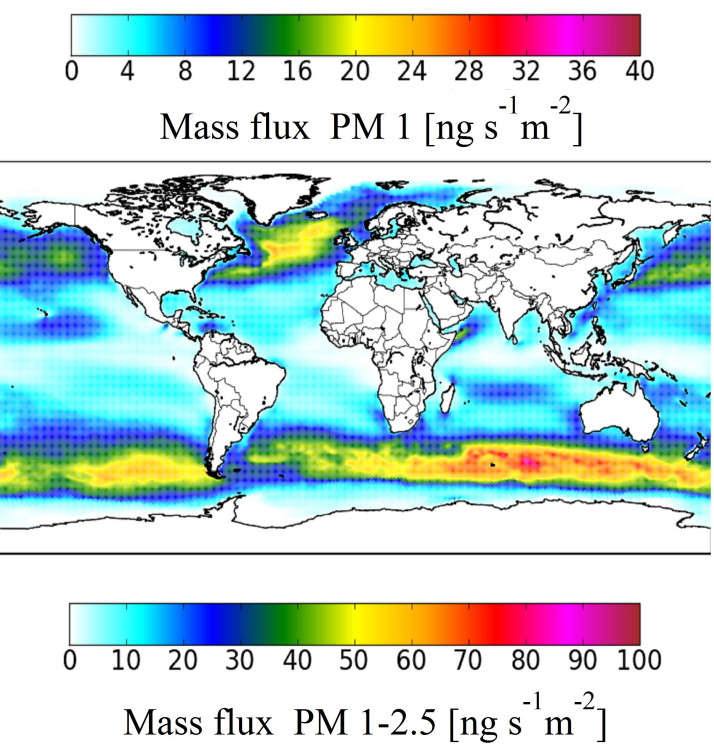

Fig. 9. Annual mean production flux of SSA computed using the OSSA-SSSF together with ECMWF meteorological and wave information: (a) Number flux of particles smaller than $1 \mu \mathrm{m}$; (b) Mass flux of particles smaller than $1 \mu \mathrm{m}$; (c) Mass flux of particles between 1-2.5 $\mu \mathrm{m}$.

et al. (2011) SSSF is much lower in the mid-temperature regime, but rapidly increases at higher temperatures. At this stage, it is difficult to say which dependency is more appropriate as the OSSA-SSSF SST dependency derives from first principles but is not (yet) compared to observational data
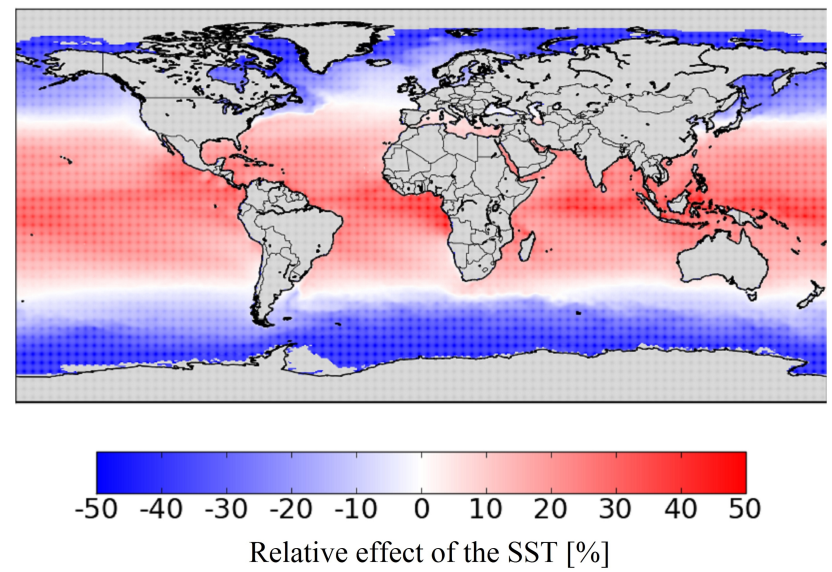

Fig. 10. The relative SST effect on the number flux of particles smaller than $1 \mu \mathrm{m}$ : colour scale represents the relative difference between the flux calculated using standard OSSA-SSSF and OSSASSSF with constant viscosity $\left(\mathrm{SST}=15^{\circ} \mathrm{C}\right.$, salinity $35 \%$ ).

representing different SST, while Jaeglé's comes from the adjustment to AOD measurements; however, AOD measurements are not a good proxy for the direct particle flux since AOD is determined by both production and subsequent processes in the atmosphere, i.e. transport, removal, and transformation due to chemical and physical processes which affect particle concentrations, size distributions, and optical properties. Also, AOD over ocean may be affected by aerosol particles of non-marine origin.

\section{Discussion}

Introducing the Reynolds number into the OSSA-SSSF brought about improvements as regards the ambiguity in the effect of wind speed and the sensitivity to other environmental parameters. First of all, the scatter at a given wind speed arising from wind history (fetch, rising or waning winds) was reduced by including the wave state in the forcing parameter. Secondly, the Reynolds number encapsulated the SST effects through the viscosity of sea water which depends on its temperature and salinity, however, effect of SST has not been validated yet. Several studies have shown the impact of SST on the SSSF (Mårtensson et al., 2003; Sellegri et al., 2006; Jaeglé et al., 2011; Zábori et al., 2012), but the results from the laboratory experiments were somewhat contradictory or at least not consistent. Mårtensson et al. (2003) showed a decrease in particle number concentration with increasing temperature for particles smaller than $0.35 \mu \mathrm{m}$, but an increase for larger particles, while Sellegri et al. (2006) indicated a different threshold at $\sim 0.07 \mu \mathrm{m}$; therefore, particles with a diameter of $\sim 0.1 \mu \mathrm{m}$ would decrease in number concentration for one SSSF, but increase for another one. At the same time, the recent study of Zábori et al. (2012) showed a decrease in number concentration for all 

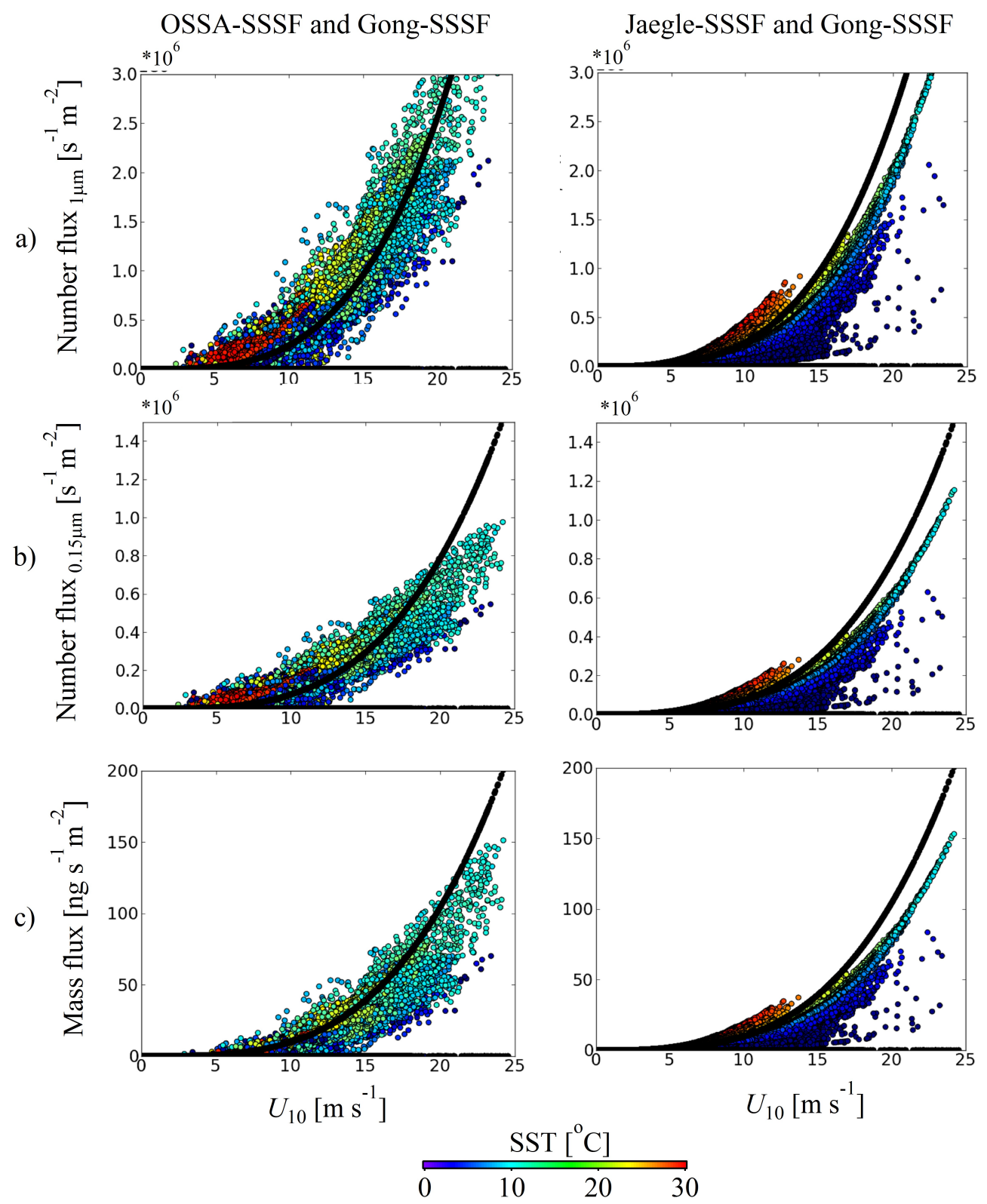

Fig. 11. Global instantaneous (2 January 2006, 00:00 UTC) SSA number and mass fluxes; Left panel: computed using the OSSA-SSSF (colour circles) overlapped with black dots representing fluxes computed using the Gong (2003) SSSF; Right panel: computed using the Jaeglé et al. (2011) SSSF (colour circles) overlapped with black dots representing fluxes computed using the Gong (2003) SSSF; Colours represent SST; (a) number flux for particles $0.07<D<1 \mu \mathrm{m}$; (b) number flux for particles $0.07<D<0.15 \mu \mathrm{m}$; (c) mass flux for particles $0.07<\mathrm{D}<1 \mu \mathrm{m}$.

particles smaller than $2.5 \mu \mathrm{m}$ with increasing temperature. In contrast, ambient mass measurement studies (Jaeglé et al., 2011 and references therein) indicated an increase in particle mass with increasing temperature. This mass-temperature dependency is similar to the temperature dependency captured in the OSSA-SSSF, where SST effects are included through the kinematic viscosity of seawater. The latter was easy to implement into the SSSF and derives from first physical principles, because the terminal velocity of a rising bub- ble is inversely proportional to the kinematic viscosity of the surrounding fluid (Hinds, 1982). Thus, bubbles in warmer waters will rise more quickly to the surface than in colder waters (e.g. bubbles of $0.04 \mathrm{~mm}$ reach terminal rise velocities of $0.28 \mathrm{~cm} \mathrm{~s}^{-1}$ and $0.53 \mathrm{~cm} \mathrm{~s}^{-1}$ at 0 and $20^{\circ} \mathrm{C}$, respectively, Lewis and Schwartz, 2004), which would increase the number of smaller bubbles reaching the surface, and thus increase the production of SSA particles (Jaeglé et al., 2011). Also Anguelova and Webster (2006) indicated that there is an 


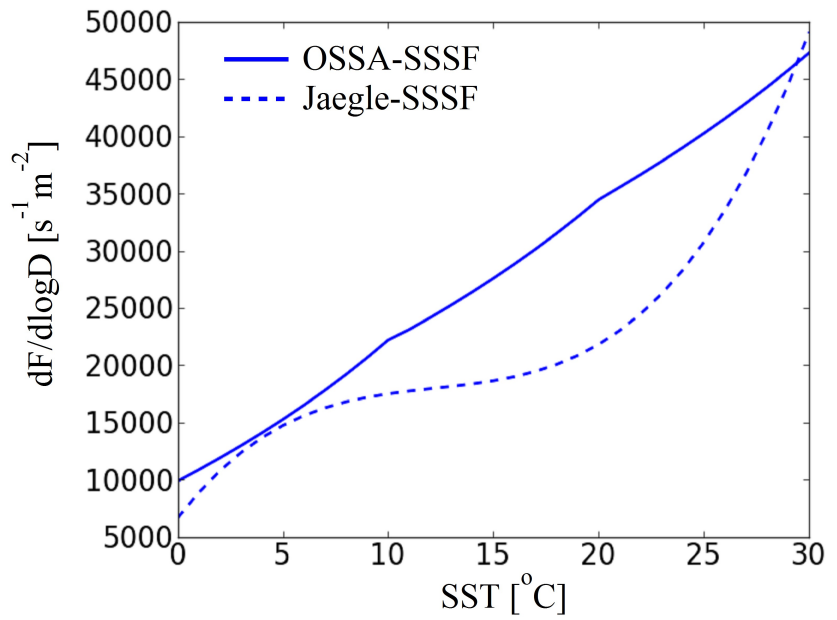

Fig. 12. Comparison of the effect of sea surface temperature (SST) on the particle production for using the OSSA-SSSF and the formulation by Jaeglé et al. (2011) for $D_{\mathrm{p}}=1 \mu \mathrm{m}$ particles at $9 \mathrm{~m} \mathrm{~s}^{-1}$ wind speed. To eliminate the effect of the wave state, which was incorporated into the OSSA-SSSF, the constant values of $C_{\mathrm{d}}=1.3 \times 10^{-3}$ and $H_{\mathrm{S}}=1.5$ were used in the calculation of the production fluxes.

effect of temperature on viscosity, resulting in higher whitecap fraction for warmer waters.

By deriving different flux- $R e_{H_{\mathrm{w}}}$ relationships for different particle size regions, this study accounted for the different effects of wind speed and its history on the shape of the SSSF because each mode had a different dependence on the Reynolds number, thus resulting in different size distributions at different wind speeds or values of the Reynolds number. In fact, the bubble bursting produces film and jet drops through different mechanisms: ejection of film droplets as the bubble cap breaks and jet droplets from the rising jet (Monahan et al., 1986; Spiel, 1994, 1997). These mechanisms produce particles of different sizes, moreover, Spiel (1994) indicated that droplet size distributions produced from air bubbles are often bimodal. In addition, film drops are produced from plunging waves, spilling waves and trough breaking, which in turn can result in different bubble spectra and, therefore, different particle distributions, as well as new SSA droplets may be produced from the splash when droplets fall back into the ocean (like raindrops do) (Marks, 1990; Lewis and Schwartz, 2004). Different wind speed onsets as stated by (Monahan et al., 1986) could also be related to different wind speed effects on the particle size distribution. In fact, this is the first time that different mode dependencies were shown in contrast to earlier studies with a single dependency for all particles.

Another important advantage of the OSSA-SSSF is that it was derived from in-situ observations, from Mace Head and SEASAW; therefore, it lacks many problems which parameterizations based on laboratory experiments are facing, in particular, the representativeness of small scale laboratory experiments for oceanic conditions. At the same time, coastal stations possess the risk of the effects of the surf zone on direct measurements of SSA fluxes. In this study, the SSA fluxes were derived from concentration measurements which are not affected by the coastal effects (Ceburnis et al., 2008). In addition, the specific topography of Mace Head minimises the influence of the surf zone as well (Rinaldi et al., 2009). Moreover, the fact that the two independent and methodologically different datasets used in this study (Mace Head and SEASAW) were so similar in the overlapping size range provided us further confidence in the results.

The present SSSF does not include organic matter which is a very important part of the sea spray aerosol, in particular for the smallest particles (Facchini et al., 2008), which can act as cloud condensation nuclei. Therefore, we suggest to use the OSSA-SSSF to obtain the total sea spray aerosol fluxes and to derive the organic fraction by using the parameterization developed by Rinaldi et al. (2013) in a way it was used before in several other studies (O'Dowd et al., 2008; Vignati et al., 2010; Gantt et al., 2011). There is also evidence that micro-organisms affect the viscosity of sea water (Seuront et al., 2010) so that biological activity may be taken into account via the viscosity, like the effect of temperature and salinity; however, further studies and parameterizations are required on this topic in order to separate the different effects and relate the viscosity to observables like chlorophyll-a concentrations.

\section{Conclusions}

The OSSA sea spray aerosol source function derived in this study covers particle sizes with dry diameters between $15 \mathrm{~nm}$ up to $6 \mu \mathrm{m}$ and encapsulates wave history, salinity, and temperature effects through using the Reynolds number as forcing parameter instead of the wind speed. For the first time, this source function shows and accounts for the distinct forcing effects on the different particle size ranges, resulting in different flux distributions for a particular $R e_{H_{\mathrm{w}}}$. The resulting SSSF provides fluxes which are on the lower side of those calculated using many other source functions developed in the last decade, yet the use of the OSSA-SSSF results in particle number and mass concentrations closer to the ones measured in real ambient conditions. Better agreement with the measurements allows producing more accurate particle number concentrations and size distributions, which in turn results in a better description of cloud condensation nucleus distributions. The latter is very important in order to reduce the uncertainty in modelling indirect effects on the earth radiative balance arising from primary production of SSA. In addition to climate effects, a correct particulate mass assignment to the natural sources, in this case primary marine sea spray aerosol production, is very important as regards air quality and source apportionment studies. 
Acknowledgements. This work was supported by the European Space Agency (Support To Science Element: Oceanflux Sea Spray Aerosol, contract No. 4000104514/11/I-AM), HEA-PRTLI4 Environment and Climate: Impact and Responses programme, and the European Commission 6th Framework programme project EUCAARI (036833-2), EC ACTRIS Research Infrastructure Action under the 7th Framework Programme, EPA-Ireland, CRAICC (Cryosphere-atmosphere interactions in a changing Arctic climate), part of the Top-level Research Initiative (TRI) of the joint Nordic research and innovation initiative. We would also like to thank Ian Brooks and Sarah Norris, University of Leeds, for making available the SEASAW data and the many discussions on the use of the data, Ernie R. Lewis (Brookhaven National Laboratory) for producing the SSSF intercomparison figure, Adrian Callaghan (Scripps Institution of Oceanography, UCSD) for the valuable comments and discussions.

Edited by: M. C. Facchini

\section{References}

Abdalla, S., Janssen, P. A. E. M., and Bidlot, J. R.: Jason2 OGDR Wind and Wave Products: Monitoring, Validation and Assimilation, Marine Geodesy, 33, 239-255, doi:10.1080/01490419.2010.487798, 239-255, 2010.

Abdalla, S., Janssen, P. A. E. M., and Bidlot, J.-R.: Altimeter Near Real Time Wind and Wave Products: Random Error Estimation, Marine Geodesy, 34, 393-406, doi:10.1080/01490419.2011.585113, 2011.

Allan, J. D., Jimenez, J. L., Williams, P. I., Alfarra, M. R., Bower, K. N., Jayne, J. T., Coe, H., and Worsnop, D. R.: Quantitative sampling using an Aerodyne aerosol mass spectrometer - 1. Techniques of data interpretation and error analysis, J Geophys ResAtmos, 108, 4090, doi:10.1029/2002jd002358, 2003.

Andreae, M. O. and Rosenfeld, D.: Aerosol-cloudprecipitation interactions. Part 1 . The nature and sources of cloud-active aerosols, Earth-Sci. Rev., 89, 13-41, doi:10.1016/j.earscirev.2008.03.001, 2008.

Andreas, E. L., Mahrt, L., and Vickers, D.: A New Drag Relation for Aerodynamically Rough Flow over the Ocean, J. Atmos. Sci., 69, 2520-2537, doi:10.1175/JAS-D-11-0312.1, 2012.

Anguelova, M. D. and Webster, F.: Whitecap coverage from satellite measurements: A first step toward modeling the variability of oceanic whitecaps, J. Geophys. Res.-Ocean., 111, C03017, doi:10.1029/2005jc003158, 2006.

Bates, T. S., Anderson, T. L., Baynard, T., Bond, T., Boucher, O., Carmichael, G., Clarke, A., Erlick, C., Guo, H., Horowitz, L., Howell, S., Kulkarni, S., Maring, H., McComiskey, A., Middlebrook, A., Noone, K., O’Dowd, C. D., Ogren, J., Penner, J., Quinn, P. K., Ravishankara, A. R., Savoie, D. L., Schwartz, S. E., Shinozuka, Y., Tang, Y., Weber, R. J., and Wu, Y.: Aerosol direct radiative effects over the northwest Atlantic, northwest Pacific, and North Indian Oceans: estimates based on in-situ chemical and optical measurements and chemical transport modeling, Atmos. Chem. Phys., 6, 1657-1732, doi:10.5194/acp-6-1657-2006, 2006.

Blanchard, D. C.: The electrification of the atmosphere by particles from bubbles in the sea, Prog. Oceanography, 1, 73-202, doi:10.1016/0079-6611(63)90004-1, 1963.
Blanchard, D. C.: Citation-Classic - the Electrification of the Atmosphere by Particles from Bubbles in the Sea, Phys. Chem. Earth, 48, p. 16, 1986.

Callaghan, A., de Leeuw, G., Cohen, L., and O'Dowd, C. D.: Relationship of oceanic whitecap coverage to wind speed and wind history, Geophys. Res. Lett., 35, 23, L23609, doi:10.1029/2008g1036165, 2008.

Ceburnis, D., O’Dowd, C. D., Jennings, G. S., Facchini, M. C., Emblico, L., Decesari, S., Fuzzi, S., and Sakalys, J.: Marine aerosol chemistry gradients: Elucidating primary and secondary processes and fluxes, Geophys. Res. Lett., 35, L07804, doi:10.1029/2008g1033462, 2008.

Clarke, A. D., Owens, S. R., and Zhou, J. C.: An ultrafine sea-salt flux from breaking waves: Implications for cloud condensation nuclei in the remote marine atmosphere, J Geophys Res-Atmos, 111, D06202, doi:10.1029/2005jd006565, 2006.

de Leeuw, G., Neele, F. P., Hill, M., Smith, M. H., and Vignali, E.: Production of sea spray aerosol in the surf zone, J. Geophys. Res.-Atmos., 105, 29397-29409, 2000.

de Leeuw, G., Andreas, E. L., Anguelova, M. D., Fairall, C. W., Lewis, E. R., O'Dowd, C., Schulz, M., and Schwartz, S. E.: Production flux of sea spray aerosol, Rev. Geophys., 49, RG2001, doi:10.1029/2010RG000349, 2011.

DeCarlo, P. F., Kimmel, J. R., Trimborn, A., Northway, M. J., Jayne, J. T., Aiken, A. C., Gonin, M., Fuhrer, K., Horvath, T., Docherty, K. S., Worsnop, D. R., and Jimenez, J. L.: Field-deployable, high-resolution, time-of-flight aerosol mass spectrometer, Anal. Chem., 78, 8281-8289, doi:10.1021/Ac061249n, 2006.

Drennan, W. M., Taylor, P. K., and Yelland, M. J.: Parameterizing the sea surface roughness, J Phys Oceanogr, 35, 835-848, doi:10.1175/Jpo2704.1, 2005.

Facchini, M. C., Rinaldi, M., Decesari, S., Carbone, C., Finessi, E., Mircea, M., Fuzzi, S., Ceburnis, D., Flanagan, R., Nilsson, E. D., de Leeuw, G., Martino, M., Woeltjen, J., and O'Dowd, C. D.: Primary submicron marine aerosol dominated by insoluble organic colloids and aggregates, Geophys. Res. Lett., 35, L17814, doi:10.1029/2008GL034210, 2008.

Foreman, R. J. and Emeis, S.: Revisiting the Definition of the Drag Coefficient in the Marine Atmospheric Boundary Layer, J. Phys. Oceanogr., 40, 10, 2325-2332, doi:10.1175/2010JPO4420.1, 2010.

Gantt, B., Meskhidze, N., Facchini, M. C., Rinaldi, M., Ceburnis, D., and O'Dowd, C. D.: Wind speed dependent size-resolved parameterization for the organic mass fraction of sea spray aerosol, Atmos. Chem. Phys., 11, 8777-8790, doi:10.5194/acp-11-87772011, 2011.

Geever, M., O’Dowd, C. D., van Ekeren, S., Flanagan, R., Nilsson, E. D., de Leeuw, G., and Rannik, U.: Submicron sea spray fluxes, Geophys. Res. Lett., 32, L15810, doi:10.1029/2005gl023081, 2005.

Goddijn-Murphy, L., Woolf, D. K., and Callaghan, A. H.: Parameterizations and algorithms for oceanic whitecap coverage, J. Phys. Oceanogr., 41, 742-756, doi:10.1175/2010jpo4533.1, 2011.

Gong, S. L.: A parameterization of sea-salt aerosol source function for sub- and super-micron particles, Global Biogeochem. Cy., 17, 1097, doi:10.1029/2003gb002079, 2003.

Haeffelin, M., Angelini, F., Morille, Y., Martucci, G., Frey, S., Gobbi, G. P., Lolli, S., O’Dowd, C. D., Sauvage, L., Xueref- 
Remy, I., Wastine, B., and Feist, D. G.: Evaluation of mixingheight retrievals from automatic profiling lidars and ceilometers in view of future integrated networks in Europe, Bound-Lay. Meteorol., 143, 49-75, doi:10.1007/s10546-011-9643-z, 2012.

Hill, M. K., Brooks, B. J., Norris, S. J., Smith, M. H., Brooks, I. M., and De Leeuw, G.: A Compact Lightweight Aerosol Spectrometer Probe (CLASP), J Atmos Ocean Tech, 25, 1996-2006, doi:10.1175/2008jtecha1051.1, 2008.

Hinds, W. C.: Aerosol Technology John Wiley and Sons, New York, 424 pp., 1982.

Hoppel, W. A., Frick, G. M., and Fitzgerald, J. W.: Surface source function for sea-salt aerosol and aerosol dry deposition to the ocean surface, J. Geophys. Res.-Atmos., 107, 4382, doi:10.1029/2001jd002014, 2002.

IFS DOCUMENTATION - Cy37r2: http://www.ecmwf.int/ research/ifsdocs/CY37r2/IFSPart7.pdf (last access: 20 December 2013), 2011.

Jaeglé, L., Quinn, P. K., Bates, T. S., Alexander, B., and Lin, J. T.: Global distribution of sea salt aerosols: new constraints from in situ and remote sensing observations, Atmos. Chem. Phys., 11, 3137-3157, doi:10.5194/acp-11-3137-2011, 2011.

Janssen, P. A. E. M., Abdalla, S., Hersbach, H., and Bidlot, J.-R.: Error Estimation of Buoy, Satellite, and Model Wave Height Data, J. Atmos. Ocean. Technol., 24, 1665-1677, doi:10.1175/JTECH2069.1, 2007.

Jimenez, J. L., Jayne, J. T., Shi, Q., Kolb, C. E., Worsnop, D. R., Yourshaw, I., Seinfeld, J. H., Flagan, R. C., Zhang, X. F., Smith, K. A., Morris, J. W., and Davidovits, P.: Ambient aerosol sampling using the Aerodyne Aerosol Mass Spectrometer, J. Geophys. Res.-Atmos., 108, 8425, doi:10.1029/2001JD001213, 2003.

Keene, W. C., Maring, H., Maben, J. R., Kieber, D. J., Pszenny, A. A. P., Dahl, E. E., Izaguirre, M. A., Davis, A. J., Long, M. S., Zhou, X. L., Smoydzin, L., and Sander, R.: Chemical and physical characteristics of nascent aerosols produced by bursting bubbles at a model air-sea interface, J. Geophys. Res.-Atmos., 112, D21202, doi:10.1029/2007jd008464, 2007.

Kleefeld, C., O’Dowd, C. D., O'Reilly, S., Jennings, S. G., Aalto, P., Becker, E., Kunz, G., and de Leeuw, G.: Relative contribution of submicron and supermicron particles to aerosol light scattering in the marine boundary layer, J. Geophys. Res.-Atmos., 107, 8103, doi:10.1029/2000jd000262, 2002.

Lewis, E. R. and Schwartz, S. E.: Sea salt aerosol production: mechanisms, methods, measurements and models, Geophys. Monogr. Ser., AGU, Washington, D. C, 413 pp., 2004.

Limpert, E., Stahel, W. A., and Abbt, M.: Log-normal Distributions across the Sciences: Keys and Clues, Bioscience, 51, 341-352, doi:10.1641/0006-3568(2001)051[0341:LNDATS]2.0.CO;2, 2001.

Manders, A. M. M., Schaap, M., Querol, X., Albert, M. F. M. A., Vercauteren, J., Kuhlbusch, T. A. J., and Hoogerbrugge, R.: Sea salt concentrations across the European continent, Atmos Environ, 44, 20, 2434-2442, doi:10.1016/j.atmosenv.2010.03.028, 2010.

Marks, R.: Preliminary investigations on the influence of rain on the production, concentration, and vertical distribution of sea salt aerosol, Journal of Geophysical Research: Oceans, 95, 2229922304, doi:10.1029/JC095iC12p22299, 1990.
Mårtensson, E. M., Nilsson, E. D., de Leeuw, G., Cohen, L. H., and Hansson, H. C.: Laboratory simulations and parameterization of the primary marine aerosol production, J Geophys Res-Atmos, 108, 4297, doi:10.1029/2002JD002263, 2003.

Middlebrook, A. M., Bahreini, R., Jimenez, J. L., and Canagaratna, M. R.: Evaluation of composition-dependent collection efficiencies for the aerodyne aerosol mass spectrometer using field data, Aerosol Sci. Technol., 46, 258-271, doi:10.1080/02786826.2011.620041, 2012.

Milroy, C., Martucci, G., Lolli, S., Loaec, S., Sauvage, L., XuerefRemy, I., Lavric, J. V., Ciais, P., and O'Dowd, C. D.: An assessment of pseudo-operational ground-based light detection and ranging sensors to determine the boundary-layer structure in the coastal atmosphere, Advances in Meteorology, 2012, 929080, 18, doi:10.1155/2012/929080, 2012.

Monahan, E. C. and Muircheartaigh, I. O.: Optimal power-law description of oceanic whitecap coverage dependence on windspeed, J. Phys. Oceanogr., 10, 12, 2094-2099, 1980.

Monahan, E. C., Spiel, D. E., and Davidson, K. L.: A model of marine aerosol generation via whitecaps and wave disruption, Oceanic Whitecaps and Their Role in Air-Sea Exchange Processes, edited by: Monahan, E. C., G. MacNiocaill, Reidel, Dordrecht, the Netherlands, 167-174, 1986.

Mulcahy, J. P., O’Dowd, C. D., Jennings, S. G., and Ceburnis, D.: Significant enhancement of aerosol optical depth in marine air under high wind conditions, Geophys. Res. Lett., 35, L16810, doi:10.1029/2008g1034303, 2008.

Nilsson, E. D., Rannik, U., Swietlicki, E., Leck, C., Aalto, P. P., Zhou, J., and Norman, M.: Turbulent aerosol fluxes over the Arctic Ocean 2. Wind-driven sources from the sea, J Geophys ResAtmos, 106, 32139-32154, 2001.

Norris, S. J., Brooks, I. M., de Leeuw, G., Smith, M. H., Moerman, M., and Lingard, J. J. N.: Eddy covariance measurements of sea spray particles over the Atlantic Ocean, Atmos Chem Phys, 8, 3, 555-563, 2008.

Norris, S. J., Brooks, I. M., Hill, M. K., Brooks, B. J., Smith, M. H., and Sproson, D. A. J.: Eddy covariance measurements of the sea spray aerosol flux over the open ocean, J. Geophys. Res.-Atmos., 117, D07210, doi:10.1029/2011jd016549, 2012.

O'Connor, T. C., Jennings, S. G., and O'Dowd, C. D.: Highlights of fifty years of atmospheric aerosol research at Mace Head, Atmos. Res., 90, 338-355, doi:10.1016/j.atmosres.2008.08.014, 2008.

O'Dowd, C. D., Lowe, J. A., Smith, M. H., and Kaye, A. D.: The relative importance of non-sea-salt sulphate and sea-salt aerosol to the marine cloud condensation nuclei population: An improved multi-component aerosol-cloud droplet parametrization, Q. J. Roy. Meteor. Soc., 125, 1295-1313, 1999.

O’Dowd, C. D., Langmann, B., Varghese, S., Scannell, C., Ceburnis, D., and Facchini, M. C.: A combined organic-inorganic sea-spray source function, Geophys. Res. Lett., 35, L01801, doi:10.1029/2007GL030331, 2008.

O'Dowd, C. D., Ceburnis, D., Ovadnevaite, J., Rinaldi, M., and Facchini, M. C.: Do anthropogenic or coastal aerosol sources impact on a clean marine aerosol signature at Mace Head?, Atmos. Chem. Phys. Discuss., 13, 7311-7347, doi:10.5194/acpd13-7311-2013, 2013.

Ovadnevaite, J., Ceburnis, D., Canagaratna, M., Berresheim, H., Bialek, J., Martucci, G., Worsnop, D. R., and O'Dowd, C.: On the effect of wind speed on submicron sea salt mass concentra- 
tions and source fluxes, J. Geophys. Res.-Atmos., 117, D16201, doi:10.1029/2011jd017379, 2012.

Partanen, A.-I., Dunne, E. M., Bergman, T., Laakso, A., Kokkola, H., Ovadnevaite, J., Sogacheva, L., Baisnée, D., Sciare, J., Manders, A., O'Dowd, C., de Leeuw, G., and Korhonen, H.: Global modelling of direct and indirect effects of sea spray aerosol using a source function encapsulating wave state, submitted to Atmos. Chem. Phys. Discuss., 2014.

Petelski, T. and Piskozub, J.: Vertical coarse aerosol fluxes in the atmospheric surface layer over the North Polar Waters of the Atlantic, J. Geophys. Res.-Ocean., 111, C06039, doi:10.1029/2005jc003295, 2006.

Rap, A., Scott, C. E., Spracklen, D. V., Bellouin, N., Forster, P. M., Carslaw, K. S., Schmidt, A., and Mann, G.: Natural aerosol direct and indirect radiative effects, Geophys. Res. Lett., 40, $3297-$ 3301, doi:10.1002/grl.50441, 2013.

Reid, J. S., Jonsson, H. H., Smith, M. H., and Smirnov, A.: Evolution of the vertical profile and flux of large sea-salt particles in a coastal zone, J. Geophys. Res.-Atmos., 106, 12039-12053, doi:10.1029/2000JD900848, 2001.

Rinaldi, M., Facchini, M. C., Decesari, S., Carbone, C., Finessi, E., Mircea, M., Fuzzi, S., Ceburnis, D., Ehn, M., Kulmala, M., de Leeuw, G., and O'Dowd, C. D.: On the representativeness of coastal aerosol studies to open ocean studies: Mace Head - a case study, Atmos. Chem. Phys., 9, 9635-9646, doi:10.5194/acp-99635-2009, 2009.

Rinaldi, M., Fuzzi, S., Decesari, S., Marullo, S., Santoleri, R., Provenzale, A., von Hardenberg, J., Ceburnis, D., Vaishya, A., O'Dowd, C. D., and Facchini, M. C.: Is Chlorophyll-a the Best Surrogate for Organic Matter Enrichment in Submicron Primary Marine Aerosol?, J. Geophys. Res. Atmos., 118, 4964-4973, doi:10.1002/jgrd.50417, 2013.

Sellegri, K., O'Dowd, C. D., Yoon, Y. J., Jennings, S. G., and de Leeuw, G.: Surfactants and submicron sea spray generation, J. Geophys. Res.-Atmos., 111, D22215, doi:10.1029/2005JD006658, 2006.

Seuront, L., Leterme, S. C., Seymour, J. R., Mitchell, J. G., Ashcroft, D., Noble, W., Thomson, P. G., Davidson, A. T., van den Enden, R., Scott, F. J., Wright, S. W., Schapira, M., Chapperon, C., and Cribb, N.: Role of microbial and phytoplanktonic communities in the control of seawater viscosity off East Antarctica $\left(30-80^{\circ} \mathrm{E}\right)$, Deep Sea Research Part II: Topical Studies in Oceanography, 57, 9-10, 877-886, http://dx.doi.org/10.1016/j.dsr2.2008.09.018, 2010.

Sharqawy, M. H., Lienhard V, J. H., and Zubair, S. M.: Thermophysical Properties of Sea Water: A review of existing correlations and data, Desalinization and Water Treatment, 16, 354-380, doi:10.5004/dwt.2010.1079, 2010.

Smith, M. H., Park, P. M., and Consterdine, I. E.: Marine Aerosol Concentrations and Estimated Fluxes over the Sea, Q. J. Roy. Meteor. Soc., 119, 809-824, doi:10.1256/Smsqj.51210, 1993.

Sofiev, M., Soares, J., Prank, M., de Leeuw, G., and Kukkonen, J.: A regional-to-global model of emission and transport of sea salt particles in the atmosphere, J. Geophys. Res. Atmos., 116, D21302, doi:10.1029/2010JD014713, 2011.

Spiel, D. E.: The sizes of the jet drops produced by air bubbles bursting on sea- and fresh-water surfaces, Tellus B, 46, 4, 325-338, doi:10.1034/j.1600-0889.1994.t01-2-00007.x, 1994.
Spiel, D. E.: A hypothesis concerning the peak in film drop production as a function of bubble size, J. Geophys. Res. Ocean., 102, 1153-1161, doi:10.1029/96JC03069, 1997.

Taylor, J. R.: An Introduction to Error Analysis: The study of uncertainties in physical measurements, 2nd ed., University Science books, Sausalito, CA, 1997.

Thorpe, S. A.: Bubble Clouds and the Dynamics of the Upper Ocean, Q. J. Roy. Meteor. Soc., 118, 1-22, doi:10.1002/qj.49711850302, 1992.

Tsyro, S., Aas, W., Soares, J., Sofiev, M., Berge, H., and Spindler, G.: Modelling of sea salt concentrations over Europe: key uncertainties and comparison with observations, Atmos. Chem. Phys. 11, 20, 10367-10388, doi:10.5194/acp-11-10367-2011, 2011.

Tyree, C. A., Hellion, V. M., Alexandrova, O. A., and Allen, J. O.: Foam droplets generated from natural and artificial seawaters, J. Geophys. Res.-Atmos., 112, D12204, doi:10.1029/2006JD007729, 2007.

Vaishya, A., Jennings, S. G., and O’Dowd, C.: Seasonal Variation of the Aerosol Light Scattering Coefficient in Marine Air of the Northeast Atlantic, Adv. Meteorol., 170490, doi:10.1155/2011/170490, 2011.

Vignati, E., Facchini, M. C., Rinaldi, M., Scannell, C., Ceburnis, D., Sciare, J., Kanakidou, M., Myriokefalitakis, S., Dentener, F., and O'Dowd, C. D.: Global scale emission and distribution of seaspray aerosol: Sea-salt and organic enrichment, Atmos. Environ., 44, 670-677, doi:10.1016/j.atmosenv.2009.11.013, 2010.

Wiedensohler, A., Birmili, W., Nowak, A., Sonntag, A., Weinhold, K., Merkel, M., Wehner, B., Tuch, T., Pfeifer, S., Fiebig, M., Fjaraa, A. M., Asmi, E., Sellegri, K., Depuy, R., Venzac, H., Villani, P., Laj, P., Aalto, P., Ogren, J. A., Swietlicki, E., Williams, P., Roldin, P., Quincey, P., Huglin, C., Fierz-Schmidhauser, R., Gysel, M., Weingartner, E., Riccobono, F., Santos, S., Gruning, C., Faloon, K., Beddows, D., Harrison, R. M., Monahan, C., Jennings, S. G., O’Dowd, C. D., Marinoni, A., Horn, H. G., Keck, L., Jiang, J., Scheckman, J., McMurry, P. H., Deng, Z., Zhao, C. S., Moerman, M., Henzing, B., de Leeuw, G., Loschau, G., and Bastian, S.: Mobility particle size spectrometers: harmonization of technical standards and data structure to facilitate high quality long-term observations of atmospheric particle number size distributions, Atmos. Meas. Tech., 5, 657-685, doi:10.5194/amt5-657-2012, 2012.

Woolf, D. K.: Parametrization of gas transfer velocities and sea-state-dependent wave breaking, Tellus B, 57, 87-94, doi:10.1111/j.1600-0889.2005.00139.x, 2005.

Wu, J.: Oceanic Whitecaps and Sea State, J. Phys. Oceanogr., 9, 5, 1064-1068, doi:10.1175/15200485(1979)009<1064:Owass>2.0.CO;2, 1979.

Zábori, J., Matisāns, M., Krejci, R., Nilsson, E. D., and Ström, J.: Artificial primary marine aerosol production: a laboratory study with varying water temperature, salinity, and succinic acid concentration, Atmos. Chem. Phys., 12, 10709-10724, doi:10.5194/acp-12-10709-2012, 2012.

Zhao, D. and Toba, Y.: Dependence of Whitecap Coverage on Wind and Wind-Wave Properties, J Oceanogr, 57, 603-616, doi:10.1023/A:1021215904955, 2001. 